Research Paper

\title{
Meta-analytic Evidence for the Plurality of Mechanisms in Transdiagnostic Structural MRI Studies of Hallucination Status
}

\author{
Colleen P.E. Rollins ${ }^{\text {a, } *}$, Jane R. Garrison ${ }^{\mathrm{a}, \mathrm{b}}$, Jon S. Simons ${ }^{\mathrm{b}}$, James B. Rowe ${ }^{\mathrm{c}}$, Claire O'Callaghan ${ }^{\mathrm{a}}$, \\ Graham K. Murray ${ }^{\text {a,d }}$, John Suckling ${ }^{\text {a }}$ \\ a Department of Psychiatry, University of Cambridge, Cambridge, UK \\ b Department of Psychology and Behavioural \& Clinical Neuroscience Institute, University of Cambridge, Cambridge, UK \\ c Department of Clinical Neurosciences, University of Cambridge, Cambridge, UK \\ d Cambridgeshire and Peterborough NHS Foundation Trust, UK
}

\section{A R T I C L E I N F O}

\section{Article history:}

Received 1 November 2018

Received in revised form 15 January 2019

Accepted 27 January 2019

Available online 21 February 2019

\section{Keywords:}

Hallucination

Structural MRI

Transdiagnostic

Meta-analysis

Systematic review

Psychiatric

Neurodegenerative

\begin{abstract}
A B S T R A C T
Background: Hallucinations are transmodal and transdiagnostic phenomena, occurring across sensory modalities and presenting in psychiatric, neurodegenerative, neurological, and non-clinical populations. Despite their crosscategory occurrence, little empirical work has directly compared between-group neural correlates of hallucinations.

Methods: We performed whole-brain voxelwise meta-analyses of hallucination status across diagnoses using anisotropic effect-size seed-based $d$ mapping (AES-SDM), and conducted a comprehensive systematic review in PubMed and Web of Science until May 2018 on other structural correlates of hallucinations, including cortical thickness and gyrification.

Findings: 3214 abstracts were identified. Patients with psychiatric disorders and hallucinations (eight studies) exhibited reduced gray matter (GM) in the left insula, right inferior frontal gyrus, left anterior cingulate/ paracingulate gyrus, left middle temporal gyrus, and increased in the bilateral fusiform gyrus, while patients with neurodegenerative disorders with hallucinations (eight studies) showed GM decreases in the left lingual gyrus, right supramarginal gyrus/parietal operculum, left parahippocampal gyrus, left fusiform gyrus, right thalamus, and right lateral occipital gyrus. Group differences between psychiatric and neurodegenerative hallucination meta-analyses were formally confirmed using Monte Carlo randomizations to determine statistical significance, and a jackknife sensitivity analysis established the reproducibility of results across nearly all study combinations. For other structural measures (28 studies), the most consistent findings associated with hallucination status were reduced cortical thickness in temporal gyri in schizophrenia and altered hippocampal volume in Parkinson's disease and dementia. Additionally, increased severity of hallucinations in schizophrenia correlated with GM reductions within the left superior temporal gyrus, right middle temporal gyrus, bilateral supramarginal and angular gyri.

Interpretation: Distinct patterns of neuroanatomical alteration characterize hallucination status in patients with psychiatric and neurodegenerative diseases, suggesting a plurality of anatomical signatures. This approach has implications for treatment, theoretical frameworks, and generates refutable predictions for hallucinations in other diseases and their occurrence within the general population.

Funding: None.
\end{abstract}

(c) 2019 Published by Elsevier Ltd. This is an open access article under the CC BY-NC-ND license (http://creativecommons.org/licenses/by-nc-nd/4.0/).

\section{Introduction}

Hallucinations are transdiagnostic and transmodal perceptions of stimuli that do not exist in the physical world [1]. They are prevalent in both psychiatric disorders, such as schizophrenia (60-80\%) [2] and

\footnotetext{
* Corresponding author at: Department of Psychiatry, University of Cambridge, Cambridge CB2 0SP, UK

E-mail address: cper2@cam.ac.uk (C.P.E. Rollins).
}

bipolar disorder (BD 10-23\%) [3], and neurodegenerative diseases, such as Parkinson's disease (PD; 22-38\%) [4], dementia with Lewy Bodies (DLB; 80\%) [5], and Alzheimer's disease (AD; 13-18\%) [6], as well as in other psychiatric and neurological disorders, and among the general population (4.5-12.7\%) [7]. Irrespective of diagnosis, the presence of hallucinations marks an increased risk of adverse outcomes, such as reduced likelihood of recovery in schizophrenia [8], more severe cognitive deficits in PD [9], increased mortality in AD [10], increased suicidal behaviour in adults with psychosis [11], and transition to later mental 


\section{Research in context}

\section{Evidence before This Study}

There is increasing recognition that hallucinations occur beyond the archetype of schizophrenia, presenting in other psychiatric disorders, neurological and neurodegenerative conditions, and among the general population. Not only are hallucinations a transdiagnostic phenomenon, but also the subjective experience of hallucinating is diverse, varying in modality, content, frequency, and affect. It has been suggested that no one type of hallucination is pathognomic to any one disorder, but rather that hallucinations may exist on a spectrum from health to illness, epidemiologically or experientially continuous between individuals who do and do not meet criteria for a mental illness. However, limited research has been done to directly compare the underlying neuroanatomy of hallucinations between different disorders. With this aim, we conducted a meta-analysis and systematic review of structural MRI studies comparing individuals who experience hallucinations with those who do not, to investigate the brain morphology related to the transdiagnostic presentation of hallucinations. We searched PubMed and Web of Science with no start date limit, up to May 2018, using the keyword combination (hallucinat*) AND (MRI OR magnetic resonance imaging OR morphology OR voxel?based OR morphometr* OR neural correlate OR structur*). We included only studies with a within-diagnosis no-hallucination control to tease out structural changes specific to hallucinations from effects of the broader pathology. Neuroimaging meta-analyses were conducted on studies performing whole-brain voxelwise gray matter differences, while studies assessing other structural correlates were qualitatively synthesized.

\section{Added Value of this Study}

This is the first meta-analysis to illustrate the brain structural correlates of hallucination occurrence derived from T1-weighted magnetic resonance imaging (MRI) in a comparative manner across clinical groups. We identified two distinct gray matter substrates for hallucination presence in psychiatric compared to neurodegenerative diseases, which we hypothesize constitute at least two distinct mechanisms. In addition, we qualitatively assessed other structural neuroimaging studies over a variety of morphometric indices. We therefore provide a complete characterization of current knowledge of the brain morphology associated with hallucinations across clinical status and modality.

\section{Implications of all the Available Evidence}

Our findings show at least two structural substrates that link to the hallucinatory experience. This informs theoretical work on hallucinations which have to date been limited in generating unifying direction-specific predictions of brain structure and function. Understanding the plurality of anatomical signatures of hallucinations may also inform treatment strategies. We predict that other disorders in which patients experience hallucinations can be categorized by our approach based on the broader phenotype; for example, hallucinations in personality disorder may be of the psychiatric type, and similarly for early onset hallucinations in the general population, whilst later onset will be neurodegenerative. Moreover, by differentiating the mechanisms of hallucinations we recommend the contextualizing of research by the appropriate phenotype. illness in children and young adults [12,13]. Although hallucinations are often distressing, they may also be benign or contribute to meaningful personal experiences $[14,15]$.

Historically, hallucinations were considered a cardinal symptom of schizophrenia, but they are not pathognomic: one-third of patients do not hallucinate [2], and the experience is often heterogeneous among those who do [1]. This has been confirmed across clinical and nonclinical populations, revealing diverse phenomenology involving modality, content, affect, onset, and frequency $[1,15,16]$. Inter-individual differences among hallucinations prompt a number of conceptual, mechanistic, and clinical questions: Does phenomenological heterogeneity translate into neurobiological plurality? How would this influence theoretical models of hallucinations and inform treatments? Does the epidemiological and experiential diversity of hallucinations reflect a continuum model, in which symptoms like hallucinations are distributed over a spectrum of individuals who do and do not meet criteria for mental illness, and thus arise from a common mechanism instantiated to different degrees of severity [17]? Establishing the validity of this conceptual framework against alternatives is important for how we understand and treat hallucinations.

Despite the plurality of hallucinations, there is little empirical work comparing between-group neural correlates of hallucinations. Prior reviews and meta-analyses on the brain structural and functional correlates of hallucinations have generally limited their scope to a single diagnosis or modality [18-20], or both [21-25]. Only two reviews have investigated hallucinations transdiagnostically or in more than one modality: one without quantitative meta-analytic comparison [26], the other focussed on acute functional correlates of hallucinations [27]. Two meta-analyses have explored the structural correlates of hallucinations, but assessed correlates of hallucination severity rather than presence/absence, and limited their scope to auditory verbal hallucinations $(\mathrm{AVH})$ in schizophrenia $[23,24]$. We therefore planned metaanalyses to evaluate MRI-derived volumetric structural gray matter (GM) correlates of hallucination status across populations, complemented with a comprehensive review of other structural measures, including cortical thickness, gyrification, and structure-specific morphometrics.

A significant issue in neuroimaging studies of hallucinations has been the lack of a clinical control group, thus confounding abnormalities specific to hallucination status with those of the broader phenotype. Equally challenging has been a tangled conceptual landscape, with numerous models proposed as cognitive or neurobiological accounts of auditory or visual hallucinations [5,26,28-41] (Fig. 1). Though an influential model of auditory hallucinations is the inner speech model [45], which proposes that AVHs arise from misattributing inner speech to a non-self source, alternative models posit the causal agent to be memory-related processes [28], spontaneous activation in auditory and related memory areas [29], inappropriate proximal salience [30], skewed balance of top-down/bottom-up control dynamics between secondary sensory cortices and frontal regions $[26,33]$ or of inhibition/ excitation at the physiological level [34], or the mismatch between processes comparing predictive representations of the external world to sensory evidence $[31,35,37]$. While these models attempt to explain auditory hallucinations in schizophrenia and non-clinical populations, a separate array of models have been proposed for visual hallucinations in neurodegenerative disorders like PD and AD [5,32,36,46]. Auditory and visual hallucination models overlap in alluding to deficits in reality monitoring, memory, salience, inhibition, and excitation. Additionally, hallucinations have been subcategorized by different neurocognitive mechanisms [40], or by differential contribution of a range of pharmacological systems [41]. Obtaining differentiating evidence is difficult as these models are not mutually exclusive, each drawing upon a similar repertoire of constituents, making it non-trivial to derive corresponding predictions [42]. However, specific morphological variation can differentiate patients who do and do not hallucinate [43], indicating that structural MRI can provide insights into why individuals hallucinate. 


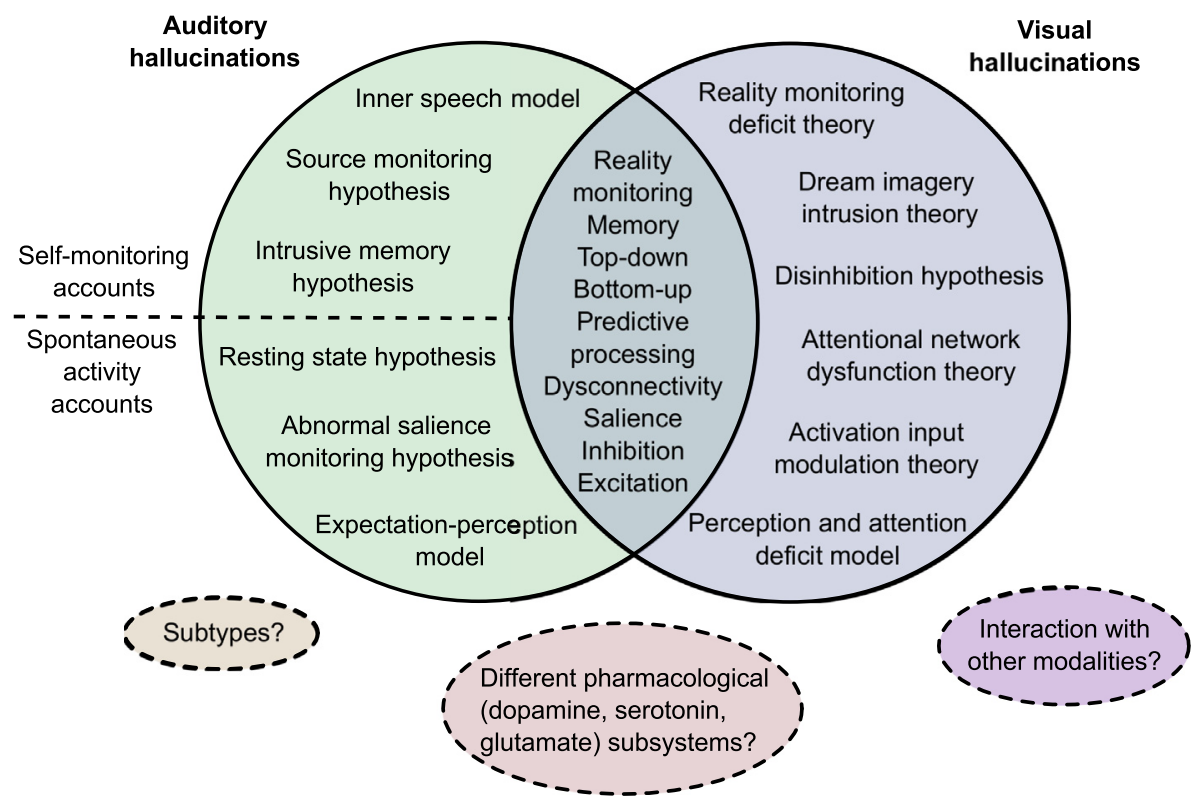

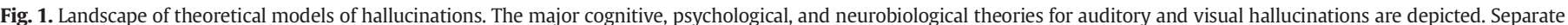

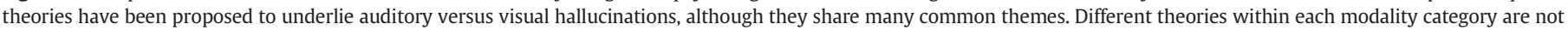

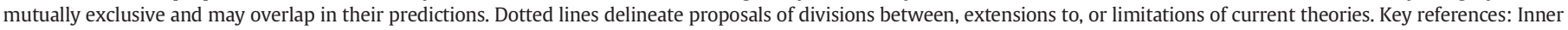

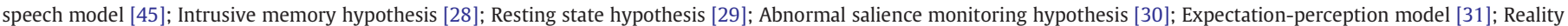

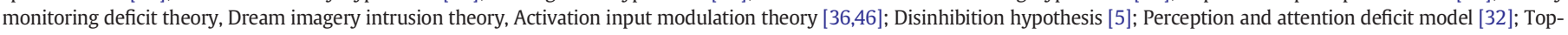

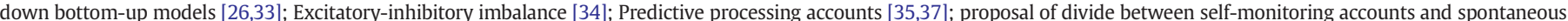

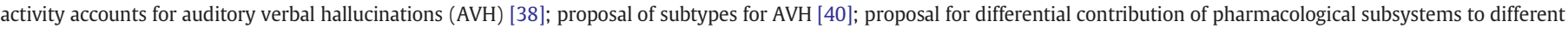
types of AVH [41]; commentary on need to address interaction between and hierarchy of different modalities of hallucinations [40].

Voxel-based morphometry (VBM) is a common method for unbiased, automated quantification of GM differences between groups. Conducting a meta-analysis of VBM studies is an objective approach to synthesize the extant literature and identify replicable findings [44]. Knowledge of neuroanatomical signatures of hallucinations present in certain populations and absent in others would clarify the continuum model by identifying whether there exist common neural correlates and contribute towards a clearer neurobiological picture of the origins and mechanisms of hallucinations. Considering the cultural and historical influences on hallucination interpretation [14], an organic model of hallucinations could moreover substantiate accurate diagnostic criteria. This meta-analysis and systematic review quantitatively compared people with and without hallucinations in terms of brain structure to identify the neuroanatomy related to the transdiagnostic presence of hallucinations.

\section{Methods}

\subsection{Search Strategy and Selection Criteria}

A systematic review of the literature for the structural correlates of hallucinations was conducted in October 2017, with update notifications received until May 2018. Following PRISMA guidelines [47], articles were identified by searching PubMed and Web of Science using the keyword combination (hallucinat*) AND (MRI OR magnetic resonance imaging OR morphology OR voxel?based OR morphometr* OR neural correlate OR structur*) with no date limit. Reviews and metaanalyses on neuroimaging of hallucinations were cross-referenced to ensure no relevant studies were missed [20,23-26].

Studies were included in the meta-analyses if they: (a) employed structural MRI in a whole-brain investigation of voxelwise differences in GM reported in standard stereotaxic space; (b) included a direct comparison between groups with and without hallucinations within the same diagnostic category. Corresponding authors were contacted to request coordinate information if not reported in the original article, or to clarify methodological issues. CPER evaluated all studies and JS, GKM, or JRG confirmed the selection criteria, with uncertainties discussed to consensus. Region of interest (ROI) VBM studies and studies using non-voxelwise structural MRI methods that otherwise matched inclusion criterion (b) were included in the systematic review.

\subsection{Data Analysis}

Voxel-wise meta-analyses were undertaken using anisotropic effect-size seed-based d Mapping (AES-SDM; https://www. sdmproject.com/) [48,49] following recommended guidelines [44] (Supplementary S1). AES-SDM uses peak coordinates and effect sizes from primary studies to create maps of meta-analytic effect size and variance of the signed GM differences. Similar to other voxel-based meta-analytic methods [50], loci from primary studies are estimated as smoothed spheres and meta-analytic maxima calculated by weighting the encompassed voxels [48]. Additionally, AES-SDM incorporates the effect sign (increases or decreases) and the t-statistic associated with each peak, increasing both sensitivity and accuracy [48]. AES-SDM also allows inclusion of non-significant studies, reducing bias towards positive results. AES-SDM is detailed elsewhere (https:// www.sdmproject.com/software/tutorial.pdf), and summarized in Supplementary Methods.

Anticipating differences in mechanisms of hallucinations between psychiatric illnesses and neurodegenerative diseases based on distinctions in phenomenology, modality, prevalence [51], and the significant participant age separation among primary studies $(\mathrm{t}(25)=17.324, \mathrm{p}$ $<0.001$ ), we performed a meta-analysis including schizophrenia, first episode schizophrenia (FES), first episode psychosis (FEP), and young adults at clinical risk for psychosis (at-risk mental state long-term, ARMS-LT), and BD, and a second of neurodegenerative disorders, including PD and AD. Of the 16 studies included in these two crosssectional meta-analyses, three (see Table 1 ) did not make an explicit comparison between a hallucination $(\mathrm{H})$ and no-hallucinations $(\mathrm{NH})$ group, though the majority of patients in each group respectively either 
Table 1

Demographic and clinical characteristics of included studies.

\begin{tabular}{|c|c|c|c|c|c|c|c|}
\hline Group & Study & Sample & $\mathrm{N}$ & Age (SD) & $\mathrm{M} / \mathrm{F}$ & Hallucination Assessment Scale (Timescale) & Modality \\
\hline \multirow[t]{16}{*}{ Psychiatric } & \multirow[t]{2}{*}{ Garrison et al., 2015 [43] } & SCZ-H & 79 & $38.5(9.8)$ & $65 / 14$ & \multirow[t]{2}{*}{ Clinical interview (lifetime history) } & \multirow[t]{2}{*}{ Mixed } \\
\hline & & SCZ-NH & 34 & $40.7(9.8)$ & $27 / 7$ & & \\
\hline & \multirow[t]{2}{*}{ Gaser et al., 2004 [59] } & SCZ-H & 29 & 36.2 & $52 / 33^{e}$ & \multirow{2}{*}{ SAPS (variable up to weeks before/after scanning) } & \multirow{2}{*}{ Auditory } \\
\hline & & SCZ-NH & 56 & $(10.9)^{\mathrm{e}}$ & & & \\
\hline & \multirow[t]{2}{*}{ Shapleske et al., 2002 [60] } & SCZ-H & 41 & $35.5(8.8)$ & 41 & \multirow[t]{2}{*}{ SAPS (course of illness) } & \multirow[t]{2}{*}{ Auditory } \\
\hline & & SCZ-NH & 31 & $32.0(7.5)$ & 31 & & \\
\hline & \multirow{2}{*}{$\begin{array}{l}\text { van Swam et al., } 2012^{\mathrm{c}, \mathrm{d}} \\
\text { [52] }\end{array}$} & SCZ-H & 10 & $40.9(8.8)$ & $5 / 5$ & \multirow[t]{2}{*}{ PANSS, semi-structured interview (course of illness) } & \multirow[t]{2}{*}{ Auditory } \\
\hline & & SCZ-NH & 10 & $36.3(5.6)$ & $7 / 3$ & & \\
\hline & \multirow[t]{2}{*}{ van Tol et al., 2014 [61] } & SCZ-H & 31 & $33.4(12.5)$ & $27 / 4$ & \multirow[t]{2}{*}{ PANSS (previous week) } & \multirow{2}{*}{ Auditory } \\
\hline & & SCZ-NH & 20 & $35.0(9.7)$ & $17 / 3$ & & \\
\hline & \multirow[t]{2}{*}{ Huang et al., 2015 [62] } & FES-H & 18 & $22.6(6.7)$ & $10 / 8$ & \multirow[t]{2}{*}{ PANSS, HAHRS (previous month) } & \multirow[t]{2}{*}{ Auditory } \\
\hline & & FES-NH & 18 & $22.7(3.9)$ & $9 / 9$ & & \\
\hline & \multirow{2}{*}{$\begin{array}{l}\text { Smieskova et al., } 2012^{\text {b, d }} \\
\text { [53] }\end{array}$} & FEP-H & 16 & $25.1(4.6)$ & $12 / 4$ & \multirow[t]{2}{*}{ BRPS (variable) } & \multirow[t]{2}{*}{ Auditory } \\
\hline & & ARMS-LT-NH & 13 & $24.6(2.2)$ & $8 / 5$ & & \\
\hline & \multirow[t]{2}{*}{ Neves et al., 2016 [63] } & BD-H & 9 & $37.7(12.1)$ & $3 / 6$ & \multirow[t]{2}{*}{ MINI-Plus (lifetime history) } & \multirow[t]{2}{*}{ Auditory or visual } \\
\hline & & BD-NH & 12 & $39.9(15.0)$ & $6 / 6$ & & \\
\hline \multirow[t]{16}{*}{ Neurodegenerative } & \multirow[t]{2}{*}{ Goldman et al., 2014 [64] } & PD-H & 25 & $74.8(6.0)$ & $17 / 8$ & \multirow[t]{2}{*}{ MDS-UPDRS (at least previous month) } & \multirow[t]{2}{*}{ Mixed } \\
\hline & & PD-NH & 25 & $75.4(6.1)$ & $18 / 7$ & & \\
\hline & Meppelink et al., 2011 & PD-H & 11 & Not & Not & NPI (previous month) & Visual \\
\hline & {$[65]$} & PD-NH & 13 & reported & reported & & \\
\hline & Pagonbarraga et al., 2014 & PD-H & 15 & $64.1(9)$ & Not & MDS-UPDRS (previous month) & Passage and/or \\
\hline & {$[66]$} & PD-NH & 27 & $66.3(8)$ & reported & & presence \\
\hline & Ramirez-Ruiz et al., 2007 & PD-H & 18 & Not & $8 / 12$ & NPI Spanish version, semi-structured interview & Visual \\
\hline & {$[67]$} & PD-NH & 20 & reported & $7 / 11$ & (previous year) & \\
\hline & Watanabe et al., 2013 & PD-H & 13 & $66.6(5.5)$ & $7 / 6$ & UPDRS (not specified) & Visual \\
\hline & {$[68]$} & PD-NH & 13 & $63.6(10.7)$ & $5 / 8$ & & \\
\hline & Shin et al., 2012 [69] & nPD-H & 46 & $71.3(5.9)$ & $26 / 38$ & NPI (not specified) & Visual \\
\hline & & nPD-NH & 64 & $70.7(5.7)$ & $18 / 9$ & & \\
\hline & Lee et al., 2016 ${ }^{\mathrm{a}, \mathrm{d}}[54]$ & AD-H & 17 & $74.3(7.3)$ & $4 / 13$ & NPI Korean version (at least previous month) & Auditory or visual \\
\hline & & $\mathrm{AD}-\mathrm{NH}$ & 25 & $72.4(9.4)$ & $6 / 19$ & & \\
\hline & Blanc et al., 2014 [70] & $\mathrm{AD}-\mathrm{H}$ & 39 & $76.0(7.4)$ & $20 / 19$ & NPI (previous month) & Auditory or visual \\
\hline & & $\mathrm{AD}-\mathrm{NH}$ & 39 & $76.4(7.2)$ & $20 / 19$ & & \\
\hline
\end{tabular}

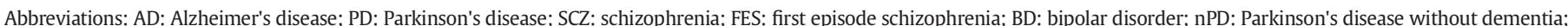

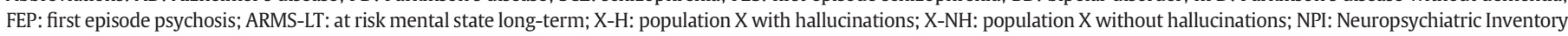

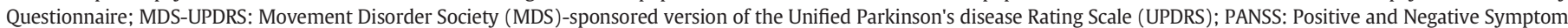

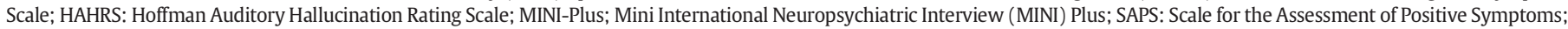
BRPS: Brief Psychiatric Rating Scale.

a Lee et al. (2016) compared AD patients with misidentification subtype to AD patients without psychosis, though they classified AD patients with hallucination into the misidentification subtype.

b Smieskova et al. (2012) compared FEP to ARMS-LT participants, though the groups differed significantly ( $<<0.0001)$ in their hallucination score, with the FEP group having a mean

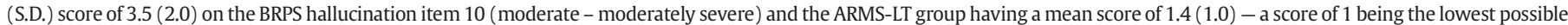
score.

c Van Swam et al. (2012) used voxel-wise cortical thickness, as opposed to VBM. Though a different analysis, VWCT and VBM are considered complementary methods [97].

d Studies considered proxy comparisons between hallucinating and non-hallucinating groups.

e For total sample of patients with schizophrenia, including both $\mathrm{H}$ and $\mathrm{NH}$.

did or did not have hallucinations, and were therefore included [52-54]. A jackknife sensitivity analysis was performed on the meta-analyses to test reproducibility of significant brain regions by iteratively repeating the statistical analysis systematically excluding one study [55]. Finally, we formally assessed group differences between psychiatric and neurodegenerative hallucination meta-analyses using Monte Carlo randomizations to determine statistical significance [56] and performed a conjunction analysis of the simple overlap between meta-analyses to detect whether there were GM differences common to both psychiatric and neurodegenerative hallucinations [57-58].

\subsection{Role of The Funding Source}

There was no funding source for this study. CPER had full access to all the data in the study and had final responsibility for the decision to submit for publication.

\section{Results}

The literature search identified 2259 articles from PubMed and 1785 from Web of Science, for a merged total of 3214 after duplicates were excluded (Fig. 2). 99 articles were selected for whole text retrieval after title/abstract screening. 16 studies met criteria for the metaanalyses [43,52-54,59-71] (see Table 1 for sample characteristics;
Table 2 for analysis details and results summary) and 28 papers ( 18 psychiatric; 10 neurodegenerative) for the systematic review of other structural metrics comparing groups with and without hallucinations.

In psychiatric patients with hallucinations, relative to those without, GM reductions were identified in the left insula, right inferior frontal gyrus (IFG), left anterior cingulate/paracingulate gyrus, and left middle temporal gyrus (MTG), while GM increases were observed in bilateral fusiform gyrus (Table 3, Fig. 3). Significant decreases in GM were apparent in six brain regions in patients with neurodegenerative disorders with hallucinations compared to those without: (1) left lingual gyrus; (2) right supramarginal gyrus/parietal operculum; (3) left fusiform gyrus; (4) left parahippocampal gyrus; (5) right thalamus; (6) right lateral occipital gyrus (Table 3, Fig. 3). Individuals with psychiatric relative to neurodegenerative hallucinations showed decreased GM in the left insula and anterior cingulate/paracingulate gyrus, and greater GM in the right lingual gyrus, IFG, and supramarginal gyrus, left thalamus, fusiform gyrus, inferior occipital gyrus, parahippocampal and hippocampal gyri, and bilateral SFG (Table 4, Fig. 3). There were no regions of GM alterations that were common to hallucination status between the psychiatric and neurodegenerative meta-analyses.

28 studies employed a regional and/or non-voxelwise approach to evaluate structural MRI data with respect to hallucination status: seven studies performed VBM restricted to predefined ROIs [43,63, 71-75], one performed source-based morphometry [76], nine explored 


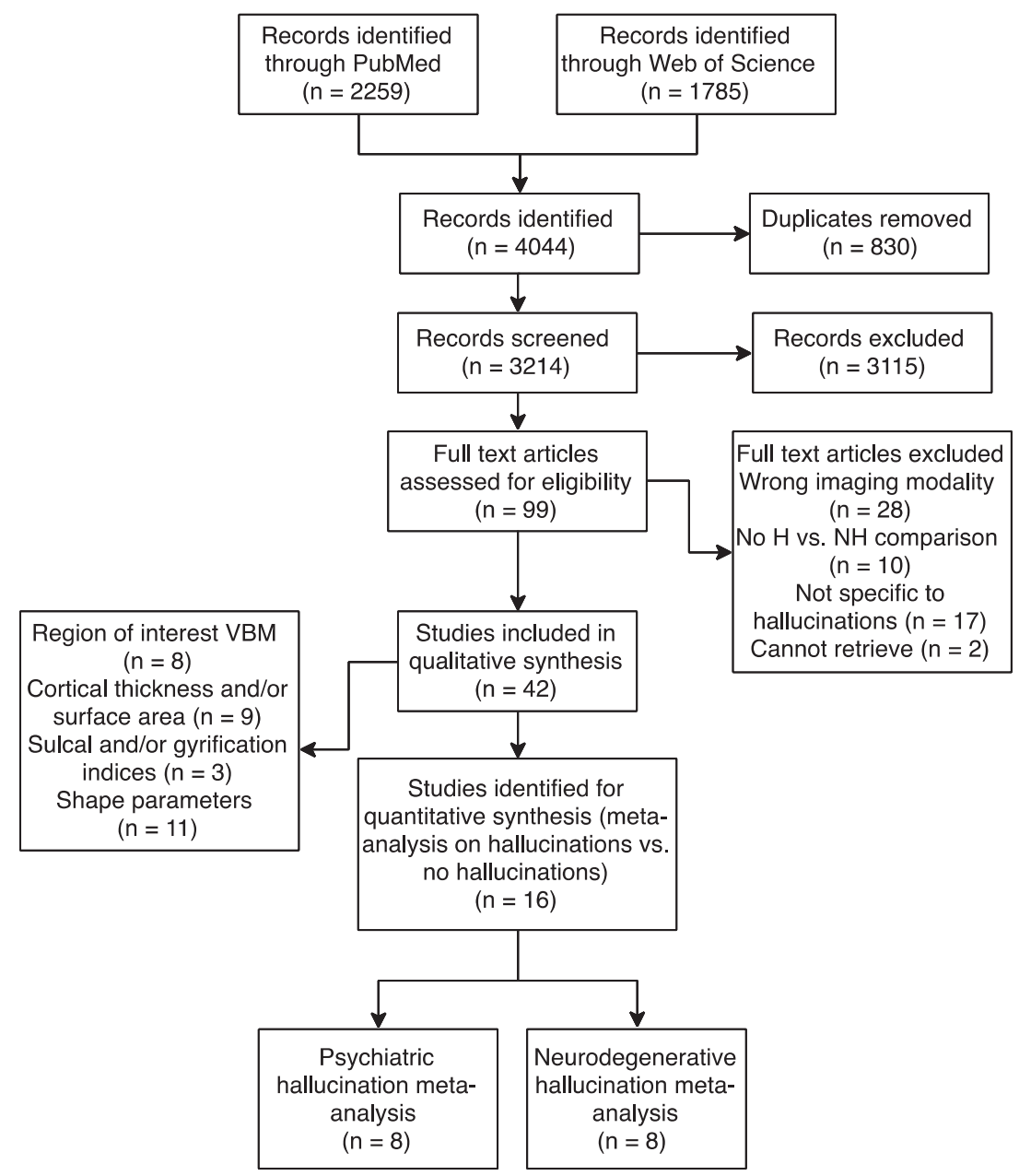

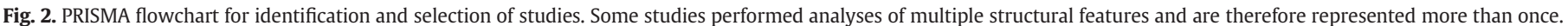
Abbreviations: $\mathrm{H}$ : population with hallucinations; $\mathrm{NH}$ : population without hallucination; VBM: voxel-based morphometry.

cortical thickness (CT) and/or surface area [77-85], three investigated gyral/sulcal properties [43,86,87], and 11 assessed structure-specific shape parameters $[43,83,85,88-95]$. Results are summarized in Tables 5-6. Overall, findings were heterogeneous, with few direct replications. In schizophrenia, the most consistent findings were reductions in CT in the vicinity of the left or right temporal gyrus for patients with hallucinations compared to those without [77,78,96], coincident with the reductions in GM in left MTG observed in the meta-analysis (Fig. 3). However, two studies reported increases in GM in temporal regions with hallucinations [90,92]. Hallucinations in PD and DLB were characterized by distributed patterns of cortical thinning $[83,84]$ and related to hippocampal volume, though the direction of this association was mixed $[83,85]$.

\section{Discussion}

Distinctive patterns of neuroanatomical alteration characterize hallucination status in patients with psychiatric and neurodegenerative diseases, with the former associated with fronto-temporal deficits and the latter with medial temporal, thalamic and occipital deficits. These results broadly align with prior meta-analyses investigating GM correlates of hallucination severity of AVH in schizophrenia, which found negative correlations between hallucination severity in schizophrenia and GMV within the bilateral STG, bilateral HG, and bilateral insula $[23,24,26]$ (Supplementary S3-4) and qualitative reviews on structural imaging studies of visual hallucinations $(\mathrm{VH})$ in neurodegenerative illnesses, which found GM atrophy associated with VH in patients with PD in parietal, hippocampal, and occipito-temporal regions, primarily the lingual and fusiform gyri $[25,98]$. The distributed pattern of structural changes seen in both hallucination signatures is suggestive of impairment in the coordination of information flow. Indeed, AVH in schizophrenia has been associated with increased functional activation in the STG, insula, anterior cingulate, and pre/post central gyrus [21,22], reduced resting connectivity between default mode regions [99], disruptions to the salience network [30], and altered interactions between resting-state networks [99]. Compared to $\mathrm{AVH}, \mathrm{VH}$ in schizophrenia have been associated with increased seed-based functional connectivity between the amygdala and visual cortex [100], among the hippocampus, $\mathrm{MPFC}$, and caudate nuclei and white matter connectivity between the hippocampus and visual areas [91], as well as decreased global sulcation in the right hemisphere [87]. VH in PD have been associated with increased functional activity in the lingual gyrus, cuneus, and fusiform gyrus [27], and hyperconnectivity in the default mode network [101]. Cortical thickness studies lend further support for divergent structural patterns, showing localized decreases in CT in temporal regions in schizophrenia spectrum disorders and more widespread decreases in dementia and PD (Table 6).

We reviewed the brain structural abnormalities associated with hallucinations, yet how changes to the brain's topological substrate translate to changes in an individual's experiential landscape remain unknown. Our findings are consistent with multiple models of hallucinations (Fig. 1). For instance, volume loss in temporal regions could 
Table 2

Imaging characteristics and key results of included studies.

\begin{tabular}{|c|c|c|c|c|c|c|c|c|c|}
\hline Group & Study & $\mathrm{T}$ & Software & Covariates & $\begin{array}{l}\text { FWHM } \\
(\mathrm{mm})\end{array}$ & Statistical Threshold & $\begin{array}{l}\text { Original } \\
\text { stereotaxic } \\
\text { space }\end{array}$ & $\begin{array}{l}\mathrm{n} \\
\text { Foci }\end{array}$ & Main result \\
\hline \multirow[t]{8}{*}{ Psychiatric } & $\begin{array}{l}\text { Garrison } \\
\text { et al., } 2015 \\
{[43]}\end{array}$ & 1.5 & SPM8 & TIV & 8 & $\begin{array}{l}\mathrm{p}<0.001 \text {, uncorrected; } \\
\text { minimum cluster size } \\
=100 \text { voxels }\end{array}$ & MNI & 2 & $\mathrm{H}>\mathrm{NH}$ : bilateral occipital lobe \\
\hline & $\begin{array}{l}\text { Gaser et al., } \\
2004 \text { [59] }\end{array}$ & 1.5 & SPM99 & $\begin{array}{l}\text { SANS total score, } \\
\text { SAPS total score } \\
\text { without auditory } \\
\text { hallucination } \\
\text { sub-items, gender }\end{array}$ & 8 & $\begin{array}{l}\mathrm{p}<0.001, \text { uncorrected } \\
\mathrm{k}=100 \text { voxels }\end{array}$ & Talairach & 4 & $\begin{array}{l}\mathrm{H}<\mathrm{NH} \text { : L transverse temporal (Heschl's) } \\
\text { gyrus R middle/inferior frontal gyrus, L } \\
\text { midde temporal gyrus, L paracingulate } \\
\text { gyrus, }\end{array}$ \\
\hline & $\begin{array}{l}\text { Shapleske } \\
\text { et al., } 2002 \\
\text { [60] }\end{array}$ & 1.5 & AFNI & Age, handedness & -4.2 & $\begin{array}{l}\text { Absolute value of } \\
\text { standard error }<1.96\end{array}$ & Talairach & 1 & $\mathrm{H}<\mathrm{NH}$ : L insular cortex \\
\hline & $\begin{array}{l}\text { van Swam } \\
\text { et al., } 2012 \\
{[52]}\end{array}$ & 3 & $\begin{array}{l}\text { Brain } \\
\text { Voyager } \\
\text { QX } 1.9\end{array}$ & None & $\begin{array}{l}\text { Not } \\
\text { reported }\end{array}$ & $\begin{array}{l}\mathrm{p}<0.05 \text {, cluster size } \\
>15 \text { voxels, corrected } \\
\text { for multiple } \\
\text { comparisons } \\
\text { (Bonferroni } \mathrm{p}<0.0063 \text { ) }\end{array}$ & MNI & 7 & $\begin{array}{l}\mathrm{H}>\mathrm{NH} \text { : L middle frontal gyrus, L posterior } \\
\text { cingulate gyrus, L frontal insula, } \mathrm{L} \\
\text { parahippocampal gyrus, } \mathrm{L} \text { postcentral } \\
\text { sulcus, } \mathrm{R} \text { visual cortexH }<\mathrm{NH} \text { : posterior } \\
\text { inferior temporal sulcus, postcentral gyrus }\end{array}$ \\
\hline & $\begin{array}{l}\text { van Tol et al., } \\
2014[61]\end{array}$ & 3 & SPM8 & Age, sex & 8 & $\begin{array}{l}\mathrm{p}<0.05 \text {, FWE-corrected } \\
\text { (cluster level), } \\
\text { voxel-wise threshold of } \\
\mathrm{p}<0.005 \text { uncorrected }\end{array}$ & MNI & 3 & $\mathrm{H}<\mathrm{NH}:$ L putamen \\
\hline & $\begin{array}{l}\text { Huang et al., } \\
2015[62]\end{array}$ & 3 & SPM8 & $\begin{array}{l}\text { Age, gender, years } \\
\text { of education }\end{array}$ & 8 & $\mathrm{p}<0.001$, uncorrected & Talairach & 0 & n.s. \\
\hline & $\begin{array}{l}\text { Smieskova } \\
\text { et al., } 2012 \\
{[53]}\end{array}$ & 3 & SPM8 & $\begin{array}{l}\text { Age, gender, total } \\
\text { GMV }\end{array}$ & 8 & $\begin{array}{l}\mathrm{p}<0.001 \text {, uncorrected } \\
\text { (cluster-forming } \\
\text { threshold); } \mathrm{p}<0.05 \\
\text { FWE-corrected }\end{array}$ & MNI & 3 & $\begin{array}{l}\mathrm{H}<\mathrm{NH} \text { : L parahippocampal gyrus } \\
\mathrm{H}>\mathrm{NH} \text { : L superior frontal gyrus, L caudate }\end{array}$ \\
\hline & $\begin{array}{l}\text { Neves et al., } \\
2016[63]\end{array}$ & 1.5 & SPM8 & Total GMV & 8 & $\begin{array}{l}\mathrm{p}<0.05 \text {, whole-brain } \\
\text { FWE-corrected }\end{array}$ & $\begin{array}{l}\text { Not } \\
\text { reported }\end{array}$ & 0 & n.s. \\
\hline \multirow[t]{8}{*}{ Neurodegenerative } & $\begin{array}{l}\text { Goldman } \\
\text { et al., } 2014 \\
{[64]}\end{array}$ & 1.5 & SPM8 & TIV & 8 & $\begin{array}{l}\mathrm{p}<0.01 \text {, uncorrected; } \\
\text { cluster extent threshold } \\
\mathrm{k}=10\end{array}$ & Talairach & 18 & $\begin{array}{l}\mathrm{H}<\mathrm{NH} \text { : bilateral cuneus, bilateral fusiform } \\
\text { gyrus, bilateral inferior parietal lobule, } \\
\text { bilateral precentral gyrus, bilateral middle } \\
\text { occipital gyrus, R lingual gyrus, bilateral } \\
\text { cingulate gyrus, L paracentral lobule }\end{array}$ \\
\hline & $\begin{array}{l}\text { Meppelink } \\
\text { et al., } 2011 \\
\text { [65] }\end{array}$ & 3 & SPM5 & Total GM & 10 & $\begin{array}{l}\mathrm{p}<0.05 \text {, brain-volume } \\
\text { corrected cluster-level }\end{array}$ & MNI & 0 & n.s. \\
\hline & $\begin{array}{l}\text { Pagonbarraga } \\
\text { et al., } 2014 \\
{[66]}\end{array}$ & 1.5 & SPM5 & $\begin{array}{l}\text { Age, gender, global } \\
\text { GMV }\end{array}$ & 12 & $\begin{array}{l}\mathrm{p}<0.001 \text {, uncorrected; } \\
\text { cluster size }=207 \\
\text { voxels (determined by } \\
1000 \text { Monte Carlo } \\
\text { simulations) }\end{array}$ & MNI & 4 & $\begin{array}{l}\mathrm{H}<\mathrm{NH} \text { : R vermis, } \mathrm{R} \text { precuneus } \\
\mathrm{H}>\mathrm{NH} \text { : posterior lobe of cerebellum, } \mathrm{L} \text { inf. } \\
\text { frontal cortex }\end{array}$ \\
\hline & $\begin{array}{l}\text { Ramirez-Ruiz } \\
\text { et al., } 2007 \\
\text { [67] }\end{array}$ & 1.5 & SPM2 & $\begin{array}{l}\text { TIV, MMSE, } \\
\text { Hamilton score, } \\
\text { Hoehn and Yahr } \\
\text { score }\end{array}$ & 12 & $\begin{array}{l}\mathrm{p}<0.05 \text {, corrected } \\
\text { cluster } \mathrm{p} \text {-level }\end{array}$ & Talairach & 3 & $\begin{array}{l}\mathrm{H}<\mathrm{NH} \text { : bilateral sup. parietal lobe, } \mathrm{L} \\
\text { lingual gyrus }\end{array}$ \\
\hline & $\begin{array}{l}\text { Watanabe } \\
\text { et al., } 2013 \\
{[68]}\end{array}$ & 3 & SPM8 & TIV, age, sex & 8 & $\begin{array}{l}\mathrm{p}<0.01 \text {, FWE corrected; } \\
\text { cluster size }>50 \text { voxels } \\
\text { and } z \text {-scores } \geq 3.00\end{array}$ & MNI & 15 & $\begin{array}{l}\mathrm{H}<\mathrm{NH} \text { : bilateral middle frontal gyrus, } \mathrm{L} \\
\text { cingulate gyrus, } \mathrm{R} \text { inferior parietal lobule, } \\
\text { bilateral cuneus, L fusiform gyrus, L } \\
\text { posterior lobe, } \mathrm{L} \text { inferior occipital gyrus, L } \\
\text { inferior frontal gyrus, L declive, R lingual } \\
\text { gyrus }\end{array}$ \\
\hline & $\begin{array}{l}\text { Shin et al., } \\
2012 \text { [69] }\end{array}$ & 3 & SPM8 & $\begin{array}{l}\text { Age, sex, PD } \\
\text { duration, } \\
\text { intracerebral } \\
\text { volume, K-MMSE } \\
\text { score }\end{array}$ & 6 & $\begin{array}{l}\mathrm{p}<0.05 \text {, FWE corrected; } \\
\text { uncorrected } \mathrm{p}< \\
0.001 \text { at the voxel level, } \\
\text { minimum cluster size } \\
=100 \text { voxels }\end{array}$ & Talairach & 5 & $\begin{array}{l}\mathrm{H}<\mathrm{NH} \text { : R inferior frontal gyrus, } \mathrm{L} \\
\text { thalamus, L uncus, L parahippocampal } \\
\text { gyrus }\end{array}$ \\
\hline & $\begin{array}{l}\text { Lee et al., } \\
2016[54]\end{array}$ & 3 & SPM8 & $\begin{array}{l}\text { Age, gender, } \\
\text { education, TIV, CDR } \\
\text { score, NPI } \\
\text { non-psychotic } \\
\text { scores }\end{array}$ & 8 & $\begin{array}{l}\mathrm{p}<0.001 \text {, uncorrected; } \\
\text { extent threshold of } \\
\text { contiguous } 100 \text { voxels } \\
(\mathrm{k}>100)\end{array}$ & MNI & 6 & $\begin{array}{l}\mathrm{H}<\mathrm{NH} \text { : } \mathrm{R} \text { inferior parietal lobule, } \mathrm{R} \text { lingual } \\
\text { gyrus, } \mathrm{L} \text { cuneus, } \mathrm{R} \text { middle frontal gyrus, } \mathrm{R} \\
\text { superior occipital gyrus, } \mathrm{R} \text { middle } \\
\text { temporal gyrus }\end{array}$ \\
\hline & $\begin{array}{l}\text { Blanc et al., } \\
2014[70]\end{array}$ & 1.5 & SPM12b & Age, total GMV & 8 & $\begin{array}{l}\mathrm{p}<0.001 \text {, uncorrected; } \\
\text { minimum cluster size } \\
=25 \text { voxels }\end{array}$ & MNI & 3 & $\begin{array}{l}\mathrm{H}<\mathrm{NH} \text { : } \mathrm{R} \text { insula/inferior frontal gyrus, } \mathrm{L} \\
\text { superior frontal gyrus, bilateral lingual } \\
\text { gyrus }\end{array}$ \\
\hline
\end{tabular}

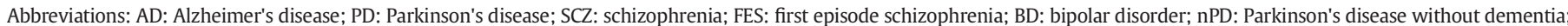

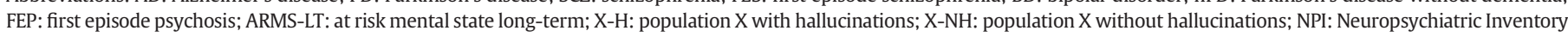

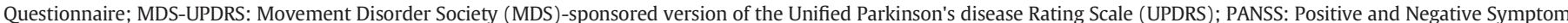

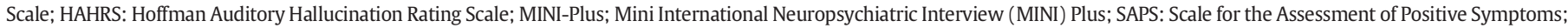

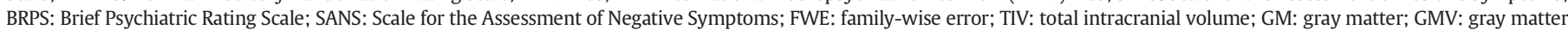
volume; CDR: Clinical Dementia Rating scale; MMSE: Mini-Mental State Examination; K-MMSE: Korean version of MMSE; L: left; R: right. 
Table 3

Regions of significant differences in gray matter between patients with hallucinations compared to those without for psychiatric and neurodegenerative disorders.

\begin{tabular}{|c|c|c|c|c|c|c|c|}
\hline \multirow[t]{2}{*}{ Group } & \multirow[t]{2}{*}{ Contrast } & \multirow[t]{2}{*}{ Region } & \multicolumn{4}{|c|}{ Peak local maximum } & \multirow{2}{*}{$\begin{array}{l}\text { Jackknife } \\
\text { sensitivity } \\
\text { analysis }^{\mathrm{a}}\end{array}$} \\
\hline & & & $\begin{array}{l}\text { MNI } \\
\text { coordinate }\end{array}$ & $\begin{array}{l}\text { Cluster size (no. of } \\
\text { voxels) }\end{array}$ & $\begin{array}{l}\text { SDM } \\
\text { Z-score }\end{array}$ & $\begin{array}{l}\text { Uncorrected } \\
\text { p-value }\end{array}$ & \\
\hline \multirow[t]{6}{*}{ Psychiatric } & \multirow[t]{4}{*}{$\mathrm{H}<\mathrm{NH}$} & L insula & $-46,2,-2$ & 820 & -1.885 & 0.0000464 & $7 / 8$ \\
\hline & & $\mathrm{R}$ inferior frontal gyrus, pars triangularis/frontal pole & $48,36,8$ & 281 & -1.464 & 0.0008257 & $7 / 8$ \\
\hline & & L anterior cingulate gyrus/paracingulate gyrus & $0,36,-2$ & 132 & -1.259 & 0.0028023 & $7 / 8$ \\
\hline & & L middle temporal gyrus & $-58,-42,-2$ & 30 & -1259 & 0.0028023 & $7 / 8$ \\
\hline & \multirow[t]{2}{*}{$\mathrm{H}>\mathrm{NH}$} & $\mathrm{R}$ fusiform gyrus & $44,-64,-18$ & 574 & 1.455 & 0.0000877 & $7 / 8$ \\
\hline & & L lateral occipital cortex/fusiform gyrus & $-40,-82,-16$ & 345 & 1.454 & 0.0000981 & $7 / 8$ \\
\hline \multirow[t]{6}{*}{ Neurodegenerative } & \multirow[t]{6}{*}{$\mathrm{H}<\mathrm{NH}$} & L lingual gyrus/intracalcarine cortex & $0,-86,-4$ & 1275 & -2.621 & 0.0000103 & $8 / 8$ \\
\hline & & L fusiform gyrus/inferior temporal gyrus & $-36,-18,-26$ & 50 & -1.860 & 0.0009702 & $7 / 8$ \\
\hline & & R supramarginal gyrus/parietal operculum & $54,-36,30$ & 75 & -1.609 & 0.0034835 & $6 / 8$ \\
\hline & & L parahippocampal gyrus & $-38,-32,-10$ & 42 & -1.740 & 0.0018579 & $7 / 8$ \\
\hline & & $\mathrm{R}$ thalamus & $2,-2,12$ & 14 & -1.637 & 0.0030603 & $7 / 8$ \\
\hline & & $\mathrm{R}$ lateral occipital cortex & $36,-80,14$ & 10 & -1.511 & 0.0043970 & $6 / 8$ \\
\hline
\end{tabular}

Abbreviations: H: Hallucinations; $\mathrm{NH}$ : No hallucinations; L: left; R: right.

a The jackknife sensitivity analysis tests the reproducibility of significant brain regions by iteratively repeating the statistical analysis, but systematically excluding one study from each replication [55]. Fractions show the number of study combinations in which the region was preserved out of the total number of dataset combinations.

reflect the misattribution of inner speech to a non-self source (inner speech model) [45], or relate to abnormalities in cortical feedback for predictive signal processing (predictive processing account) [102], or could be the result (or cause) of heightened resting state activity in the auditory cortex (resting state hypothesis) [29], or a combination of some or all of these mechanisms. That substantial heterogeneity was observed in ROI VBM hypothesis-driven studies further emphasizes the limits of current theories.

Our meta-analyses suggest that there are at least two broad biological categories of hallucination mechanism: a psychiatric mechanism and a neurodegenerative mechanism. In support, structural signatures of hallucinations in the psychiatric meta-analysis overlap with comparisons of patients to non-disordered controls. For instance, a meta-analysis of GM changes in patients with psychosis compared to healthy controls shows reductions in bilateral insula and anterior cingulate cortex [103], coinciding with regions identified in the meta-analysis of hallucinations in neurodevelopmental disorders, while thalamic, hippocampal, and occipital GM reductions in PD [104] partly coincide with the changes seen in neurodegenerative hallucinations. The relation between disorder-specific GM changes and hallucination category suggests that hallucinations share networks of brain regions with the pathologies of the disorder in which they are embedded.

Knowledge of the structural correlates of hallucination types may help understand their cognitive phenotypes. For instance, hallucinations are linked to reality monitoring, the cognitive capacity to distinguish between self-generated and external sources of information [105]. Impaired in schizophrenia, reality monitoring is associated with the structure and function of the anterior cingulate cortex [43, 105]. The cingulate gyrus is part of a network involving the IFG, ventral striatum, auditory cortex, right posterior temporal lobe whose functional connectivity is related to the subjective extent to which a hallucination feels real [106]. Indeed, we propose that connectivity is key: together with the insula, the anterior cingulate constitutes nodes of the salience network, dysfunctions in which have been proposed as central to experiencing hallucinations [30]. Structural deficits in the insula in psychosis might also underpin atypical interactions between the DMN and salience network observed in hallucinations [39]. The left STG/MTG have been robustly implicated in the manifestation of AVH $[23,102]$, emphasizing the importance of speech perception and processing in hallucinations in schizophrenia spectrum psychosis.

If hallucinations experienced by those with schizophrenia spectrum and bipolar psychosis are an example of a broader mechanism, then we predict that other neurodevelopmental disorders will have similar patterns of associated GM loss. For example, hallucinations have a prevalence of $43 \%$ in personality disorder [107], suggested to be a neurodevelopmental disorder [108], and are predicted to have a mechanism similar to other psychiatric disorders.

Abnormalities in the occipital cortex in neurodegenerative diseases suggest that deficits in sensory regions contribute to hallucinations of the associated sensory modality since $\mathrm{VH}$ are more common in $\mathrm{PD}$ than in schizophrenia [19]. Hallucinations in PD and AD were characterized by GM reduction in the thalamus and PHG. The thalamus mediates information in the cortical hierarchies via corticothalamo-cortico circuits and contributes to working memory maintenance [109], while the PHG is implicated in processing contextual associations in the service of memory formation and generating expectations about spatial relations [110]. Their involvement supports memory-related processes in hallucinations, though may equally relate to neurodegenerative pathologies. The anterior cingulate was implicated in hallucinations occurring in psychiatric disorders, but not neurodegenerative etiology. As the anterior cingulate is involved in self-referential processing, this is consistent with the observation that psychotic hallucinations address the individual and vary across continental location and historical time period $[14,111]$. Conversely, hallucinations in PD have a more passive quality and form historically stable categories of visual percepts [4].

Anatomic heterogeneity related to hallucination presence/absence has important consequences for the plurality of treatment options. A specific example is repetitive transcranial magnetic stimulation (rTMS) used to reduce hallucination frequency and severity in schizophrenia, albeit with some reservations $[112,113]$. A number of parameters including frequency of stimulation and anatomical site contribute to the outcome of rTMS, and so anatomical heterogeneity is a possible source for the ambiguity of efficacy in therapeutic trials [114]. Antipsychotic (dopamine receptor anatagonist) medication is the mainstay of treatment for hallucinations in schizophrenia, and is sometimes required in PD, with evidence of therapeutic effect in each $[115,116]$. Psychological treatments include cognitive behavioral therapy and avatar therapy. However, little is known to help guide a choice of which treatment will be tolerable and effective for a given individual; efforts to develop personalized treatment for hallucinations requires an understanding of the underlying mechanism that we suggest varies across diagnosis.

The multimodality of hallucinations is under-documented and under-researched, with $<2 \%$ of studies included in this review probing hallucinations beyond audition or vision [66]. However, 30-50\% of schizophrenia or PD patients report hallucinations in more than one modality [2,117]: olfactory hallucinations are present in $10-13.7 \%[51,118]$ and tactile sensations frequently co-occur with 


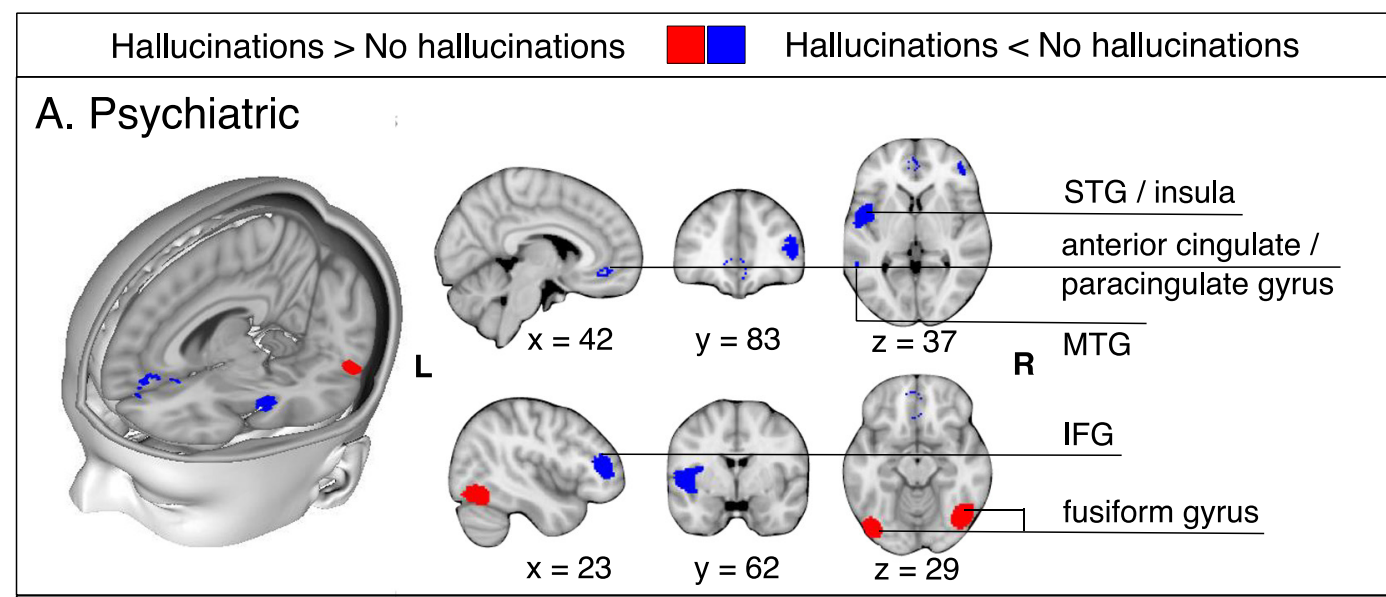

\section{B. Neurodegenerative}
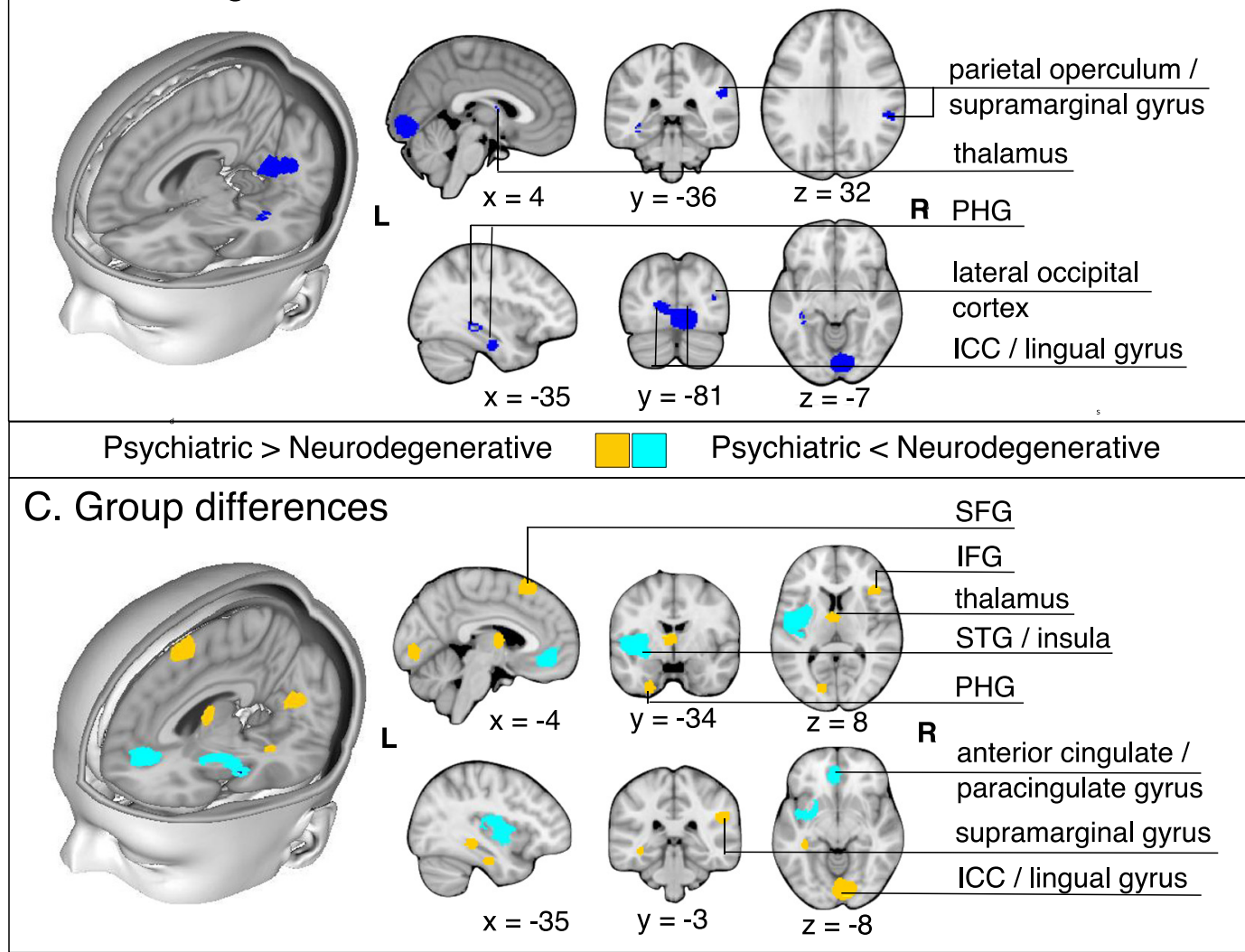

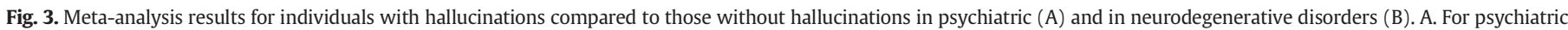

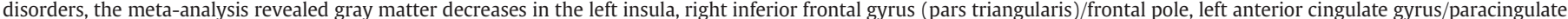

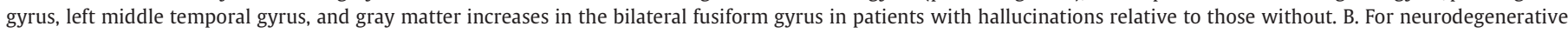

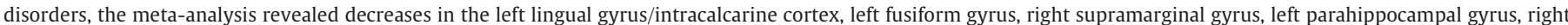

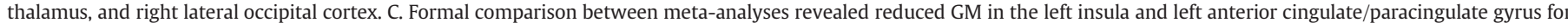

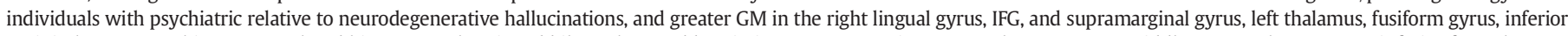

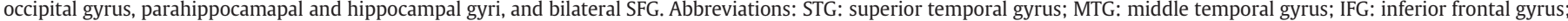
PHG: parahippocampal gyrus; ICC: intracalcarine cortex; SFG: superior frontal gyrus.

auditory hallucinations [1]. Despite the dimensionality of hallucinations, many questionnaires and theoretical models target unimodal accounts. Non-clinical individuals who hallucinate or hear voices are receiving increasing interest in scientific research [7], yet only one study in this review assessed a structural correlate (cortical thickness) of hallucinations in this population [82]. Similarly, no studies investigated brain structure or function of hallucinations in borderline personality disorder, in spite of a high point prevalence of $43 \%$ [107]. Although hallucinations are recognized to occur across diagnostic boundaries, the current scope of transdiagnostic research on hallucinations remains narrow.

The prevalence of auditory hallucinations in the general population varies across the lifespan with peaks in early life ( $<30$ years) and between 50 and 59 years [119]. Results from these meta-analyses predict that early onset of hallucinations will have a pattern of frontotemporal structural deficits similar to psychiatric disorders with neurodevelopmental origins, whilst later onset will show a neurodegenerative pattern of GM change in the occipital cortex, medial 
Table 4

Regions of significant differences in gray matter between psychiatric and neurodegenerative hallucinations.

\begin{tabular}{|c|c|c|c|c|c|}
\hline \multirow[t]{2}{*}{ Contrast } & \multirow[t]{2}{*}{ Region } & \multicolumn{4}{|c|}{ Peak local maximum } \\
\hline & & MNI coordinate & cluster size (no. of voxels) & SDM Z-score & uncorrected p-value \\
\hline \multirow[t]{2}{*}{ Psychiatric $<$ neurodegenerative } & L insula & $-42,-2,2$ & 1784 & 1.794 & $<0.0001$ \\
\hline & L anterior cingulate gyrus/paracingulate gyrus & $0,44,-10$ & 372 & 1.235 & 0.0011147 \\
\hline \multirow[t]{10}{*}{ Neurogenerative $<$ psychiatric } & $\mathrm{R}$ lingual gyrus & $4,-84,-6$ & 1080 & -2.331 & 0.0000206 \\
\hline & L superior frontal gyrus & $-10,26,64$ & 167 & -1.403 & 0.0016670 \\
\hline & R supramarginal gyrus & $52,-34,28$ & 131 & -1.365 & 0.0020230 \\
\hline & L thalamus & $-4,-4,10$ & 115 & -1.516 & 0.0008154 \\
\hline & L fusiform gyrus & $-24,-2,-42$ & 90 & -1.494 & 0.0010064 \\
\hline & $\mathrm{R}$ inferior frontal gyrus, pars triangularis & $42,24,8$ & 82 & -1.444 & 0.0013469 \\
\hline & L inferior occipital gyrus & $-44,-78,-16$ & 71 & -1.482 & 0.0010786 \\
\hline & L parahippocampal gyrus & $-32,-18,-26$ & 51 & -1.450 & 0.0013160 \\
\hline & R superior frontal gyrus & $14,36,-30$ & 34 & -1.515 & 0.0008464 \\
\hline & L hippocampus & $-36,-34,-8$ & 33 & -1.524 & 0.0007690 \\
\hline
\end{tabular}

temporal lobe and thalamus. In any case, empirical neuroimaging and cognitive research in non-clinical groups and non-dominant modalities is necessary to extend the limits of current knowledge.

As with all meta-analyses, statistical power is restricted by the size of the extant literature, both in terms of the number of studies meeting inclusion criteria and sample sizes of original studies, which in neuroimaging the experience of hallucinations remains immature. Despite this, the overall sample size was comparable to other SDM meta-analyses $(\mathrm{n}=233 \mathrm{H}, \mathrm{n}=194 \mathrm{NH}$ for psychiatric; $\mathrm{n}=128 \mathrm{H}, \mathrm{n}=162 \mathrm{NH}$ for neurodegenerative) [120,121]. Neuroimaging meta-analyses are often subject to heterogeneity in methodology. We noted broadly uniform software parameters and spatial smoothing, but variation in covariates and statistical thresholds (Table 2). However, all meta-analyses employed the same threshold throughout the brain, limiting bias towards any a-priori regions of interest and improving reliability of results. The questionnaires used to assess hallucination status varied in the time frame bounding the hallucination, from within the current week to lifetime history, and none conducted follow-up assessments for whether patients later developed hallucinations. Critically, few instruments evaluating hallucination presence distinguish between auditory and visual hallucinations or whether hallucinations occur at all in other modalities, such as tactile or olfactory. Even fewer assess specific phenomenological characteristics of hallucinations, which is potentially confounding as experiential differences may map to different neural substrates [122]. Understanding the neurobiology supporting the content of hallucinations may help in personalizing treatment strategies since hallucination content is related to cognitive profile in PD [116]. We recommend a more granular evaluation of hallucination modality, phenomenological properties, and lifetime and current history, including possible remission of hallucinations from antipsychotic medication or rTMS. The psychiatric and neurodegenerative meta-analyses illustrate cross-sectional neuroanatomical differences between patients with and without hallucinations. However, the prevalence of hallucinations increases with the duration of illness for PD [116], but generally decrease over time for schizoaffective disorder, schizophrenia, bipolar disorder, and depression [8], whilst the content may equally change over the trajectory of the disorder [116]. Future analyses of longitudinal neuroimaging data may clarify illness category separation in the temporal evolution of hallucinations. The divergence in our meta-analytic findings for psychiatric and neurodegenerative disorders may be partly attributable to differences in modality, since hallucinations experienced in schizophrenia spectrum and bipolar psychosis were predominantly auditory, while those in PD and AD were mostly visual. However, there was no overlap in brain regions identified in the two metaanalyses. Moreover, the reported modalities are partly construed by the questionnaire used, which often assume a unimodal account or neglect to ask about multimodal experiences or differentiate between hallucination modalities. A quantitative and qualitative comparison of the phenomenological properties of hallucinations in schizophrenia and PD found that $55 \%$ of patients with schizophrenia had VH and $45 \%$ of patients with PD had AH, emphasizing that sensory modality is not a mutually exclusive class [51]. Moreover, hallucinations involving more than one modality were reported in approximately $80 \%$ of patients for schizophrenia and PD alike. Differences in hallucinations between disorders emerge in the frequency, duration, capacity of control, negative valence, and impact of hallucinations on patients, such that people with schizophrenia were more heavily affected by their hallucinations [51]. It is therefore unlikely that differences between the psychiatric and neurodegenerative hallucination meta-analyses are due to modality alone, but capture a more complex picture of illness pathology, hallucination properties like content and affect, and mechanisms of onset or occurrence. Nonetheless, important outstanding questions are (1) whether hallucinations of the same modality have a common neural basis regardless of diagnosis, (2) why hallucination sensory modality prevalence rates differ between disorders, with $\mathrm{AH}$ being the most prevalent sensory modality in schizophrenia and VH for $\mathrm{PD}$, and (3) how sensory modalities interact during hallucination experiences, both in terms of their serial or simultaneous presentation in time and the underlying neural systems [123]. Finally, there was also a significant difference in the ages of the participants in the two meta-analyses, although each meta-analysis had its own agematched control group and thus the comparison between disorders did not capture differences due to aging.

Hallucinations in clinical and non-clinical populations are diverse in content, modality, frequency, and affect, among other dimensions. Though hallucinations have been explored transdiagnostically at the level of phenomenology, little empirical work has made group comparisons of brain structure related to hallucinations. We show that hallucinations in psychiatric disorders have distinct neuroanatomical organization from the pattern observed in neurodegenerative diseases, and in doing so hypothesize at least two structural substrates associated with the hallucinatory experience. This categorical differentiation in the neurobiology of hallucinations is important for optimizing or developing treatment strategies, and makes specific predictions about other disorders, such as personality disorder, and the onset of hallucinations in the general population. The structural networks involved in hallucinations partly coincide with the respective case-control comparisons, and are thus embedded within the broader neuroanatomical phenotype, emphasizing the importance of non-hallucinating patient control groups and age-matched healthy controls. Hallucinations are experienced in a variety of mental health contexts and are important phenomena in probing our perception of the external world, but theoretical work has not yet captured the diversity of hallucinations across modalities or diagnoses. By hypothesizing at least two mechanisms for hallucinations, we suggest incorporating this plurality in future research. These meta-analyses offer a critical starting point. 
Table 5

Summary of systematic review from GMV ROI studies of regional brain volume comparing individuals with and without hallucinations.

\begin{tabular}{|c|c|c|c|c|c|c|c|}
\hline Group & Study & $\begin{array}{l}\text { Sample } \\
(\mathrm{M} / \mathrm{F})\end{array}$ & $\begin{array}{l}\text { Age } \\
\text { (SD) }\end{array}$ & $\begin{array}{l}\text { Hallucination } \\
\text { modality } \\
\text { (assessment } \\
\text { scale) }\end{array}$ & $\mathrm{ROI}(\mathrm{s})$ & $\begin{array}{l}\text { Analysis } \\
\text { (imaging } \\
\text { software) }\end{array}$ & Main result \\
\hline \multirow[t]{5}{*}{ Psychiatric } & $\begin{array}{l}\text { Garrison et al., } \\
2015 \text { [43] }\end{array}$ & $\begin{array}{l}79 \\
(65 / 14) \\
\text { SCZ-H } \\
34 \\
(27 / 7) \\
\text { SCZ-NH }\end{array}$ & $\begin{array}{l}38.5 \\
(9.8) \\
40.7 \\
(9.8)\end{array}$ & $\begin{array}{l}\text { Mixed } \\
\text { (clinical } \\
\text { interview) }\end{array}$ & Medial profrontal cortex (mPFC) & $\begin{array}{l}\text { VBM } \\
(\text { SPM12) }\end{array}$ & $\begin{array}{l}\text { Gray matter volume } \\
\text { SCZ-H > SCZ-NH: mPFC region surrounding the } \\
\text { anterior PCS }\end{array}$ \\
\hline & $\begin{array}{l}\text { Cierpka et al., } 2017 \\
\text { [71] }\end{array}$ & $\begin{array}{l}10(6 / 4) \\
\text { SCZ-H } \\
10(8 / 2) \\
\text { SCZ-NH }\end{array}$ & $\begin{array}{l}36.5 \\
(9.0) \\
32.1 \\
(6.2)\end{array}$ & $\begin{array}{l}\text { Auditory } \\
\text { (BRPS, } \\
\text { PANSS, } \\
\text { PsyRatS) }\end{array}$ & Cerebellum & $\begin{array}{l}\text { VBM } \\
\text { (SPM8) }\end{array}$ & $\begin{array}{l}\text { Gray matter volume } \\
\mathrm{SCZ}-\mathrm{H}<\mathrm{SCZ}-\mathrm{NH} \text { : right lobule VIIIa }\end{array}$ \\
\hline & $\begin{array}{l}\text { Kubera et al., } 2014 \\
\text { [76] }\end{array}$ & $\begin{array}{l}10(6 / 4) \\
\text { SCZ-H } \\
10(8 / 2) \\
\text { SCZ-NH }\end{array}$ & $\begin{array}{l}36.5 \\
(9.0) \\
32.1 \\
(6.2)\end{array}$ & $\begin{array}{l}\text { Auditory } \\
\text { (BRPS, } \\
\text { PANSS, } \\
\text { PsyRatS) }\end{array}$ & $\mathrm{n} / \mathrm{a}$ & $\begin{array}{l}\text { SBM } \\
(\text { GIFT })\end{array}$ & $\begin{array}{l}\text { Gray matter volume } \\
\text { SCZ-H < SCZ-NH: component consisting MFG; } \\
\text { IFG; STG; insula; IPL; rectal gyrus; transverse } \\
\text { temporal gyrus; supramarginal gyrus; lingual } \\
\text { gyrus; postcentral gyrus; fusiform gyrus; } \\
\text { subcallosal gyrus; MTG; ITG; orbital gyrus }\end{array}$ \\
\hline & $\begin{array}{l}\text { Neves et al., } 2016 \\
\text { [63] }\end{array}$ & $\begin{array}{l}9(3 / 6) \\
\text { BD-H } \\
12(6 / 6) \\
\text { BD-NH }\end{array}$ & $\begin{array}{l}37.7 \\
(12.1) \\
39.9 \\
(15.0)\end{array}$ & $\begin{array}{l}\text { Auditory or } \\
\text { visual } \\
\text { (MINI-Plus) }\end{array}$ & $\begin{array}{l}\text { Orbitofrontal cortex and ventral } \\
\text { prefrontal areas, cingulate gyrus, } \\
\text { fusiform gyrus, superior temporal } \\
\text { sulcus, amygdala, insula, thalamus }\end{array}$ & $\begin{array}{l}\text { VBM } \\
\text { (SPM8) }\end{array}$ & $\begin{array}{l}\text { Gray matter volume } \\
\text { BD-H < BD-NH: right posterior insular cortex }\end{array}$ \\
\hline & $\begin{array}{l}\text { Stanfield et al., } \\
2009[72]\end{array}$ & $\begin{array}{l}17(\mathrm{n} / \mathrm{a}) \\
\mathrm{BD}-\mathrm{H} \\
49(\mathrm{n} / \mathrm{a}) \\
\text { BD-NH }\end{array}$ & $\begin{array}{l}36.4 \\
(11.1)^{\mathrm{a}}\end{array}$ & $\begin{array}{l}\text { Auditory } \\
\text { (OPCRIT } \\
\text { symptom } \\
\text { checklist) }\end{array}$ & Temporal lobe & $\begin{array}{l}\text { VBM } \\
\text { (SPM99) }\end{array}$ & $\begin{array}{l}\text { Gray matter density } \\
\text { BD-H < BD-NH: left middle temporal gyrus }\end{array}$ \\
\hline \multirow[t]{3}{*}{ Neurodegenerative } & $\begin{array}{l}\text { Janzen et al., } 2012 \\
\text { [73] }\end{array}$ & $\begin{array}{l}13(6 / 7) \\
\text { PD-H } \\
13(7 / 6) \\
\text { PDD-H } \\
16(9 / 7) \\
\text { PD-NH }\end{array}$ & $\begin{array}{l}66.0 \\
(6.9) \\
67.7 \\
(7.1) \\
64.3 \\
(8.0)\end{array}$ & $\begin{array}{l}\text { Visual } \\
\text { (UPDRS) }\end{array}$ & $\begin{array}{l}\text { Pedunculopontine nucleus (PPN), } \\
\text { thalamus }\end{array}$ & $\begin{array}{l}\text { VBM } \\
\text { (SPM8) }\end{array}$ & $\begin{array}{l}\text { Gray matter volume } \\
\text { PD-H + PDD-H < PD-NH: PPN, thalamus } \\
\text { PD-H < PD-NH: PPN }\end{array}$ \\
\hline & $\begin{array}{l}\text { Sanchez-Castenada } \\
\text { et al., } 2010 \text { [74] }\end{array}$ & $\begin{array}{l}6(4 / 2) \\
\text { DLB-H } \\
6(4 / 2) \\
\text { DLB-NH } \\
8(6 / 2) \\
\text { PDD-H } \\
7(4 / 3) \\
\text { PDD-NH }\end{array}$ & $\begin{array}{l}70.2 \\
(12.4) \\
71 \\
(10.7) \\
75.3 \\
(4.9) \\
70.6 \\
(7.1)\end{array}$ & Visual (NPI) & $\begin{array}{l}\text { Frontal (BA 6, 8, 9, 10, 44, 45, and } \\
47) \text {, occipital (BA 18,19), parietal } \\
\text { (BA 7, 39, 40), and temporal (20) } \\
\text { regions }\end{array}$ & $\begin{array}{l}\text { VBM } \\
\text { (SPM5) }\end{array}$ & $\begin{array}{l}\text { Gray matter volume } \\
\text { DLB-H < DLB-NH: right inferior frontal gyrus } \\
\text { (BA 45) } \\
\text { PDD-H < PDD-NH: left orbitofrontal lobe (BA } \\
\text { 10) }\end{array}$ \\
\hline & $\begin{array}{l}\text { Colloby et al., } 2017 \\
\text { [75] }\end{array}$ & $\begin{array}{l}41 \\
(26 / 15) \\
\text { DLB-H } \\
47 \\
(33 / 14) \\
\text { AD-NH }\end{array}$ & $\begin{array}{l}78.6 \\
(6.2) \\
79.0 \\
(8.8)\end{array}$ & Visual (NPI) & Substantia innomiata (SI) & $\begin{array}{l}\text { VBM } \\
\text { (SPM8) }\end{array}$ & $\begin{array}{l}\text { Gray matter volume } \\
\text { n.s. }\end{array}$ \\
\hline
\end{tabular}

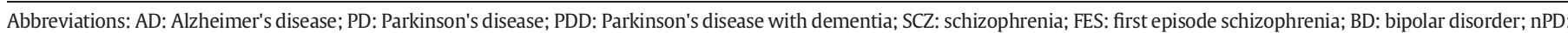

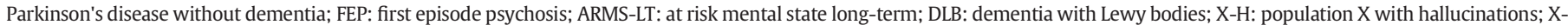

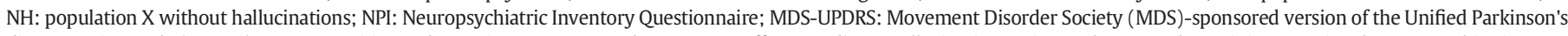

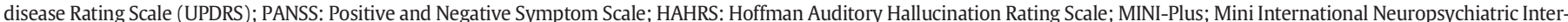

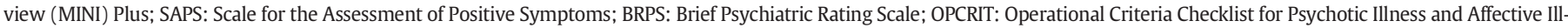

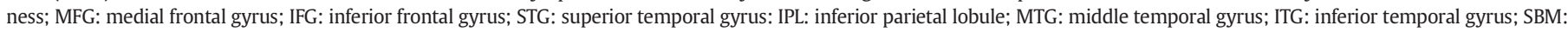
source-based morphometry.

${ }^{a}$ Hallucination and no-hallucinations groups combined.

\section{Contributors}

JS conceived and directed the project. CPER planned the search criteria, completed the literature search, data extraction, quality assessment, data analyses and summary, created the figures, and wrote the first draft of the manuscript, with input from JRG, JS, and GKM. JRG, JS, and GKM confirmed the results of data extraction. All authors critically reviewed the manuscript and contributed to its writing and revision.

\section{Declaration of Interests}

Ms. Rollins reports a scholarship from Gates Cambridge during the conduct of the study. Professor Rowe reports grants from Wellcome Trust during the conduct of the study, grants from NIHR, McDonnell
Foundation, PSP Association, Parkinsons UK, Medical Research Council, Evelyn Trust, and AZ-Medimmune, personal fees from Asceneuron, and other from Guarantors of Brain outside the submitted work. Professor Suckling, Dr. Murray, Dr. Garrison, Dr. Simons, and Dr. O'Callaghan have nothing to disclose.

\section{Acknowledgements}

The authors are supported by the following funding sources: Gates Cambridge (CPER); Wellcome Trust (JBR, 103838; CO, 200181/Z/15/Z); National Health and Medical Research Council Neil Hamilton Fairley Fellowship (CO, 1091310); Wellcome Trust Collaborative award (JRG), and a joint award from the Medical Research Council and the Wellcome Trust (JSS). 
Table 6

Summary of systematic review from non-voxelwise structural studies comparing individuals with and without hallucinations.

\begin{tabular}{|c|c|c|c|c|c|c|c|}
\hline Measure & Group & Study & $\begin{array}{l}\text { Sample } \\
(\mathrm{M} / \mathrm{F})\end{array}$ & $\begin{array}{l}\text { Age } \\
\text { (SD) }\end{array}$ & $\begin{array}{l}\text { Hallucination } \\
\text { modality } \\
\text { (Assessment } \\
\text { Scale) }\end{array}$ & Analysis (Imaging software) & Main result \\
\hline \multirow[t]{9}{*}{$\begin{array}{l}\text { Cortical } \\
\text { thickness } \\
\text { and/or } \\
\text { cortical } \\
\text { surface area }\end{array}$} & \multirow[t]{6}{*}{ Psychiatric } & $\begin{array}{l}\text { Chen et al., } \\
2015 \text { [77] }\end{array}$ & $\begin{array}{l}18(12 / 6) \\
\text { FES-H } \\
31 \\
(17 / 14) \\
\text { FES-NH }\end{array}$ & $\begin{array}{l}24.1 \\
(6.3) \\
24.3 \\
(5.9)\end{array}$ & $\begin{array}{l}\text { Auditory } \\
\text { (AHRS, } \\
\text { SAPS/SANS) }\end{array}$ & $\begin{array}{l}\text { Whole-brain vertex-wise cortical } \\
\text { thickness (Freesurfer) }\end{array}$ & \multirow{2}{*}{$\begin{array}{l}\text { Cortical thickness } \\
\text { FES-H < FES-NH: right Heschl's gyrus } \\
\text { (HG) } \\
\text { Negative correlation with } \\
\text { hallucination severity by AHRS, but } \\
\text { not SAPS/SANS scoring: Right HG } \\
\text { Cortical thickness } \\
\text { SCZ-H < SCZ-NH: left middle temporal } \\
\text { gyrus (MTG) } \\
\text { Negative correlation with } \\
\text { hallucination severity by PANSS P3, } \\
\text { but not AHRS scoring across all SCZ } \\
\text { patients: left MTG }\end{array}$} \\
\hline & & $\begin{array}{l}\text { Cui et al., } 2017 \\
{[78]}\end{array}$ & $\begin{array}{l}115 \\
(52 / 63) \\
\text { SCZ-H } \\
93 \\
(47 / 36) \\
\text { SCZ-NH }\end{array}$ & $\begin{array}{l}26.4 \\
(5.7) \\
27.3 \\
(5.1)\end{array}$ & $\begin{array}{l}\text { Auditory } \\
\text { (PANSS, } \\
\text { AHRS) }\end{array}$ & $\begin{array}{l}\text { Whole brain vertex-wise cortical } \\
\text { thickness (Freesurfer) }\end{array}$ & \\
\hline & & $\begin{array}{l}\text { Morch-Johnsen } \\
\text { et al., } 2017 \text { [79] }\end{array}$ & $\begin{array}{l}145 \\
(82 / 63) \\
\text { SCZ-H } \\
49 \\
(33 / 16) \\
\text { SCZ-NH }\end{array}$ & $\begin{array}{l}31.1 \\
(9.3) \\
30.9 \\
(8.4)\end{array}$ & $\begin{array}{l}\text { Auditory } \\
\text { (PANSS) }\end{array}$ & $\begin{array}{l}\text { ROI cortical thickness and surface area } \\
\text { analysis of bilateral Heschl's gyrus (HG), } \\
\text { planum temproale (PT) and superior } \\
\text { temporal gyrus (STG) (Freesurfer) }\end{array}$ & $\begin{array}{l}\text { Cortical thickness } \\
\text { SCZ-H }<\text { SCZ-NH: left HG } \\
\text { Cortical surface area } \\
\text { n.s. }\end{array}$ \\
\hline & & $\begin{array}{l}\text { Morch-Johnsen } \\
\text { et al., } 2018 \text { [80] }\end{array}$ & $\begin{array}{l}49 \\
(18 / 31) \\
\text { BD-H } \\
108 \\
(48 / 60) \\
\text { BD-NH }\end{array}$ & $\begin{array}{l}33.4 \\
(12.0) \\
35.0 \\
(11.4)\end{array}$ & $\begin{array}{l}\text { Auditory } \\
\text { (SCID) }\end{array}$ & $\begin{array}{l}\text { Whole-brain vertex-wise and ROI } \\
\text { cortical thickness (Freesurfer) }\end{array}$ & $\begin{array}{l}\text { Cortical thickness } \\
\text { BD-H > BD-NH: left HG (ROI) and } \\
\text { superior parietal lobule (whole-brain) } \\
\text { Cortical surface area } \\
\text { n.s. }\end{array}$ \\
\hline & & $\begin{array}{l}\text { Yun et al., } 2016 \\
\text { [81] }\end{array}$ & $\begin{array}{l}27(9 / 18) \\
\text { FEP-H } \\
24 \\
(12 / 12) \\
\text { FEP-NH }\end{array}$ & $\begin{array}{l}22.5 \\
(5.0) \\
22.7 \\
(5.1)\end{array}$ & $\begin{array}{l}\text { Auditory } \\
\text { (PANSS) }\end{array}$ & $\begin{array}{l}\text { Support vector machine using cortical } \\
\text { surface area and cortical thickness } \\
\text { measures }\end{array}$ & $\begin{array}{l}\text { Optimal feature sets of individualized } \\
\text { cortical structural covariance (ISC) } \\
\text { FEP-H vs. FEP-NH ( } 83.6 \% \text { accuracy): } 3 \\
\text { CSA-ISCs incl. The intraparietal sulcus, } \\
\text { Broca's complex, and the anterior } \\
\text { insula } \\
\text { FEP-H vs. FEP-NH ( } 82.3 \% \text { accuracy): } 6 \\
\text { CT-ISCs incl. Executive control } \\
\text { network and Wernicke's module }\end{array}$ \\
\hline & & $\begin{array}{l}\text { van Lutterveld } \\
\text { et al., } 2014 \text { [82] }\end{array}$ & $\begin{array}{l}50 \\
(19 / 31) \\
\mathrm{NC}-\mathrm{H} \\
50 \\
(19 / 31) \\
\mathrm{NC}-\mathrm{NH}\end{array}$ & $\begin{array}{l}40.8 \\
(11.6) \\
40.5 \\
(15.0)\end{array}$ & $\begin{array}{l}\text { Auditory } \\
\text { (modified } \\
\text { LSHS) }\end{array}$ & $\begin{array}{l}\text { Whole-brain vertex-wise cortical } \\
\text { thickness (Freesurfer) }\end{array}$ & $\begin{array}{l}\text { Cortical thickness } \\
\mathrm{NC}-\mathrm{H}<\mathrm{NC}-\mathrm{NH} \text { : left paracentral } \\
\text { cortex, left pars orbitalis, right } \\
\text { fusiform gyrus, right ITG, right insula }\end{array}$ \\
\hline & Neurodegenerative & $\begin{array}{l}\text { Ffytche et al., } \\
2017[83]\end{array}$ & $\begin{array}{l}21(15 / 6) \\
\text { PD-H } \\
286 \\
(192 / 94) \\
\text { PD-NH }\end{array}$ & $\begin{array}{l}64.43 \\
(7.5) \\
61.97 \\
(9.9)\end{array}$ & $\begin{array}{l}\text { Visual } \\
\text { (UPDRS) }\end{array}$ & $\begin{array}{l}\text { Whole-brain vertex-wise cortical } \\
\text { thickness (Freesurfer) }\end{array}$ & $\begin{array}{l}\text { Cortical thickness } \\
\text { PD-H < PD-NH: right supramarginal } \\
\text { gyrus, superior frontal cortex, lateral } \\
\text { occipital cortex }\end{array}$ \\
\hline & & $\begin{array}{l}\text { Delli Pizzi et al., } \\
2014 \text { [84] }\end{array}$ & $\begin{array}{l}18(9 / 9) \\
\text { DLB-H } \\
15(7 / 8) \\
\text { AD-NH }\end{array}$ & $\begin{array}{l}75.5 \\
(4.0) \\
75.6 \\
(7.6)\end{array}$ & Visual (NPI) & $\begin{array}{l}\text { Whole brain vertex-wise cortical } \\
\text { thickness (Freesurfer) }\end{array}$ & $\begin{array}{l}\text { Cortical thickness } \\
\text { DLB-H }<\text { AD-NH: right posterior } \\
\text { regions (superior parietal gyrus, } \\
\text { precuneus, cuneus, pericalcarine and } \\
\text { lingual gyri) } \\
\text { Negative correlation with } \\
\text { hallucination severity by NPI } \\
\text { hallucination item scoring in DLB } \\
\text { patients: right precuneus and superior } \\
\text { parietal gyrus }\end{array}$ \\
\hline & & $\begin{array}{l}\text { Delli Pizzi et al., } \\
2016 \text { [85] }\end{array}$ & $\begin{array}{l}19(9 / 10) \\
\text { DLB-H } \\
15(6 / 9) \\
\text { AD-NH }\end{array}$ & $\begin{array}{l}76.4 \\
(4.4) \\
76.5 \\
(7.2)\end{array}$ & Visual (NPI) & $\begin{array}{l}\text { Between group differences in cortical } \\
\text { thickness of entorhinal, } \\
\text { parahippocampal, and perirhinal } \\
\text { structures (Freesurfer) }\end{array}$ & $\begin{array}{l}\text { Cortical thickness } \\
\text { n.s. }\end{array}$ \\
\hline \multirow[t]{2}{*}{$\begin{array}{l}\text { Sulci and } \\
\text { gyrification } \\
\text { measures }\end{array}$} & \multirow[t]{2}{*}{ Psychiatric } & $\begin{array}{l}\text { Garrison et al., } \\
2015 \text { [43] }\end{array}$ & $\begin{array}{l}79 \\
(65 / 14) \\
\text { SCZ-H } \\
34(27 / 7) \\
\text { SCZ-NH }\end{array}$ & $\begin{array}{l}38.5 \\
(9.8) \\
40.7 \\
(9.8)\end{array}$ & $\begin{array}{l}\text { Mixed } \\
\text { (clinical } \\
\text { interview) }\end{array}$ & $\begin{array}{l}\text { ROI LGI of mPFC regions of interest } \\
\text { (frontopolar, medial orbitofrontal, } \\
\text { superior frontal and paracentral cortices) } \\
\text { (Freesurfer) }\end{array}$ & $\begin{array}{l}\text { Local gyrification index } \\
\text { SCZ-H }<\text { SCZ-NH: mPFC regions } \\
\text { surrounding PCS (bilateral } \\
\text { frontopolar, medial orbitofrontal, } \\
\text { superior frontal and paracentral } \\
\text { cortices) }\end{array}$ \\
\hline & & $\begin{array}{l}\text { Kubera et al., } \\
2018[86]\end{array}$ & $\begin{array}{l}10(6 / 4) \\
\text { SCZ-H } \\
10(8 / 2) \\
\text { SCZ-NH }\end{array}$ & $\begin{array}{l}36.5 \\
(9.0) \\
32.1 \\
(6.2)\end{array}$ & $\begin{array}{l}\text { Auditory } \\
\text { (BRPS, } \\
\text { PANSS, } \\
\text { PsyRatS) }\end{array}$ & $\begin{array}{l}\text { Whole-brain vertex-wise local } \\
\text { gyrification index (Freesurfer) }\end{array}$ & $\begin{array}{l}\text { Local gyrification index } \\
\text { SCZ-H < SCZ-NH: left Broca's area, } \\
\text { right Broca's homolog, right superior } \\
\text { middle frontal cortex } \\
\text { SCZ-H > SCZ-NH: precuneus and } \\
\text { superior parietal cortex }\end{array}$ \\
\hline
\end{tabular}


Table 6 (continued)

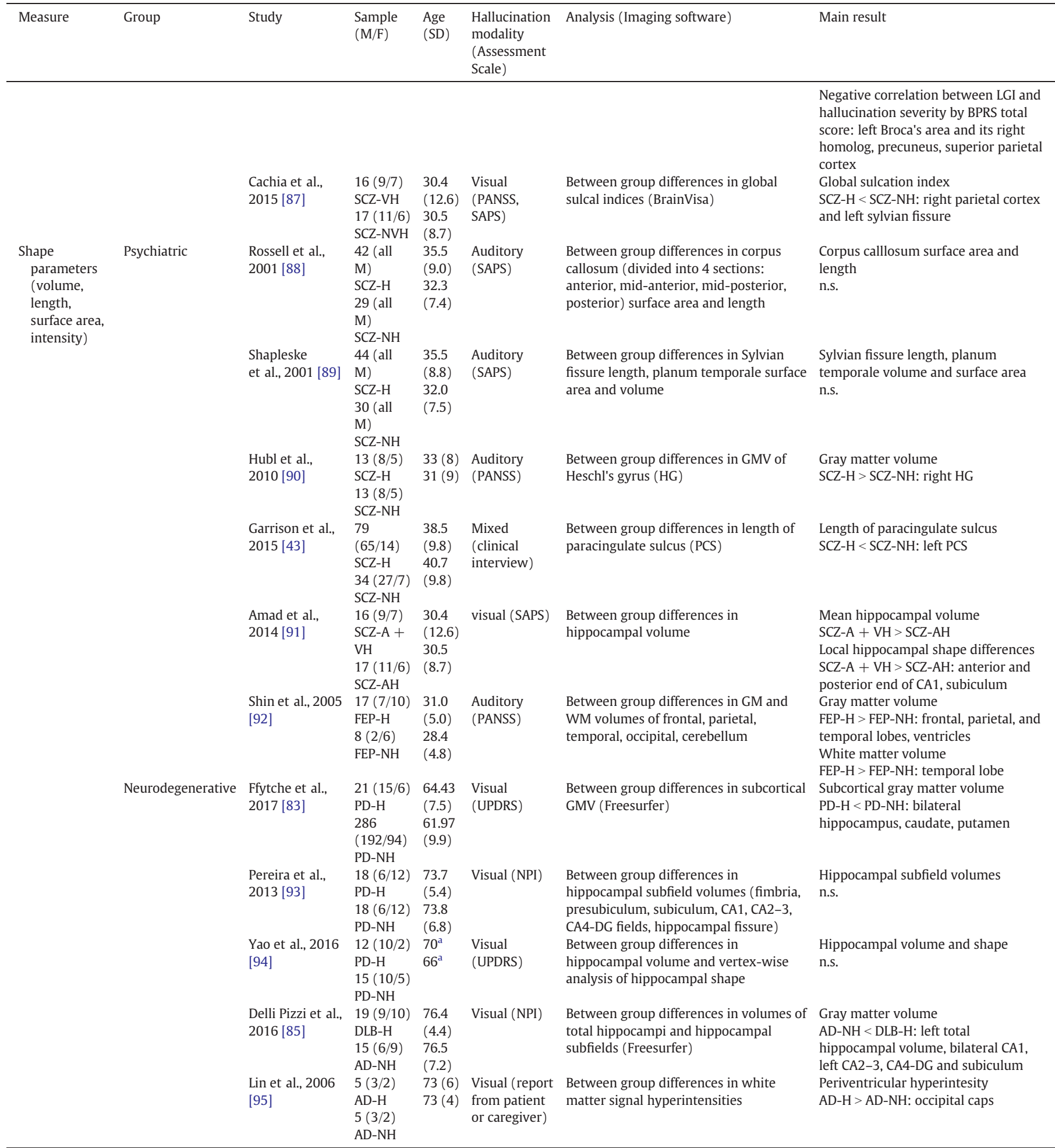

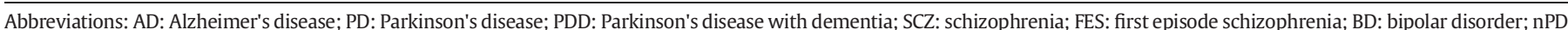

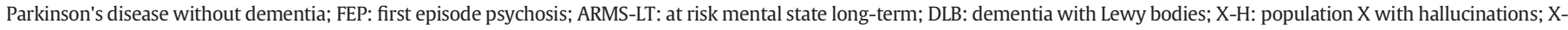

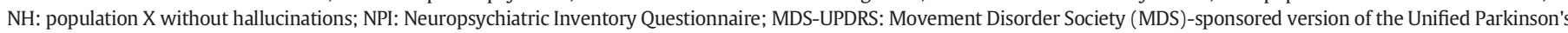

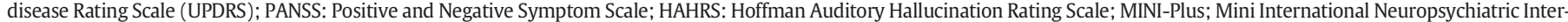

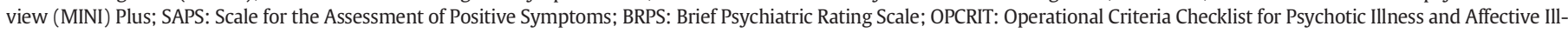

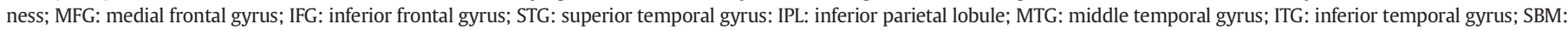
source-based morphometry. LSHS: Launay and Slade Hallucination Scale (LSHS).

a Median age. 


\section{Appendix A. Supplementary data}

Supplementary data to this article can be found online at https://doi. org/10.1016/j.eclinm.2019.01.012.

\section{References}

[1] Woods A, Jones N, Alderson-Day B, Callard F, Fernyhough C. Experiences of hearing voices: analysis of a novel phenomenological survey. Lancet Psychiatry 2015;2(4): 323-31.

[2] Lim A, Hoek HW, Deen ML, Blom JD, Investigators G. Prevalence and classification of hallucinations in multiple sensory modalities in schizophrenia spectrum disorders. Schizophr Res 2016;176(2-3):493-9.

[3] Baethge C, Baldessarini RJ, Freudenthal K, Streeruwitz A, Bauer M, Bschor T. Hallucinations in bipolar disorder: characteristics and comparison to unipolar depression and schizophrenia. Bipolar Disord 2005;7(2):136-45.

[4] Diederich NJ, Fenelon G, Stebbins G, Goetz CG. Hallucinations in Parkinson disease Nat Rev Neurol 2009;5(6):331-42.

[5] Onofrj M, Taylor JP, Monaco D, et al. Visual hallucinations in PD and Lewy body dementias: old and new hypotheses. Behav Neurol 2013;27(4):479-93.

[6] Zhao QF, Tan L, Wang HF, et al. The prevalence of neuropsychiatric symptoms in Alzheimer's disease: systematic review and meta-analysis. J Affect Disord 2016 190:264-71.

[7] Maijer K, Begemann MJH, Palmen S, Leucht S, Sommer IEC. Auditory hallucinations across the lifespan: a systematic review and meta-analysis. Psychol Med 2018;48 (6):879-88.

[8] Goghari VM, Harrow M. Twenty year multi-follow-up of different types of hallucinations in schizophrenia, schizoaffective disorder, bipolar disorder, and depression. Schizophr Res 2016:176(2-3):371-7.

[9] Wakamori T, Agari T, Yasuhara T, et al. Cognitive functions in Parkinson's disease: relation to disease severity and hallucination. Parkinsonism Relat Disord 2014;20 (4):415-20.

[10] Wilson RS, Krueger KR, Kamenetsky JM, et al. Hallucinations and mortality in Alzheimer disease. The American Journal of Geriatric Psychiatry 2005;13(11): 984-90.

[11] Kjelby E, Sinkeviciute I, Gjestad R, et al. Suicidality in schizophrenia spectrum disorders: the relationship to hallucinations and persecutory delusions. European psychiatry 2015;30(7):830-6.

[12] Jardri R, Bartels-Velthuis AA, Debbane M, et al. From phenomenology to neurophysiological understanding of hallucinations in children and adolescents. Schizophr Bull 2014;40(Suppl. 4):S221-32.

[13] Baumeister D, Sedgwick O, Howes O, Peters E. Auditory verbal hallucinations and continuum models of psychosis: a systematic review of the healthy voice-heare literature. Clin Psychol Rev 2017;51:125-41.

[14] Laroi F, Luhrmann TM, Bell V, et al. Culture and hallucinations: overview and future directions. Schizophr Bull 2014;40(Suppl. 4):S213-20.

[15] Waters F, Fernyhough C. Hallucinations: a systematic review of points of similarity and difference across diagnostic classes. Schizophr Bull 2017;43(1):32-43.

[16] Daalman K, van Zandvoort M, Bootsman F, Boks M, Kahn R, Sommer I. Auditory verbal hallucinations and cognitive functioning in healthy individuals. Schizophr Res 2011;132(2-3):203-7.

[17] van Os J, Reininghaus U. Psychosis as a transdiagnostic and extended phenotype in the general population. World Psychiatry 2016;15(2):118-24.

[18] Bohlken MM, Hugdahl K, Sommer IE. Auditory verbal hallucinations: neuroimaging and treatment. Psychol Med 2017;47(2):199-208.

[19] Waters F, Collerton D, Ffytche DH, et al. Visual hallucinations in the psychosis spectrum and comparative information from neurodegenerative disorders and eye disease. Schizophr Bull 2014;40(Suppl. 4):S233-45.

[20] Carter R, Ffytche DH. On visual hallucinations and cortical networks: a transdiagnostic review. J Neurol 2015;262(7):1780-90.

[21] Jardri R, Pouchet A, Pins D, Thomas P. Cortical activations during auditory verbal hallucinations in schizophrenia: a coordinate-based meta-analysis. Am J Psychiatry 2011;168(1):73-81

[22] Kuhn S, Gallinat J. Quantitative meta-analysis on state and trait aspects of auditory verbal hallucinations in schizophrenia. Schizophr Bull 2012;38(4):779-86.

[23] Modinos G, Costafreda SG, van Tol MJ, McGuire PK, Aleman A, Allen P. Neuroanatomy of auditory verbal hallucinations in schizophrenia: a quantitative meta-analysis of voxel-based morphometry studies. Cortex 2013;49(4): $1046-55$

[24] Palaniyappan L, Balain V, Radua J, Liddle PF. Structural correlates of auditory hallucinations in schizophrenia: a meta-analysis. Schizophr Res 2012:137(1-3):169-73.

[25] Pezzoli S, Cagnin A, Bandmann O, Structural Venneri A. Functional neuroimaging of visual hallucinations in Lewy body disease: a systematic literature review. Brain Sci 2017:7(7).

[26] Allen P, Laroi F, McGuire PK, Aleman A. The hallucinating brain: a review of structural and functional neuroimaging studies of hallucinations. Neurosci Biobehav Rev 2008;32(1):175-91.

[27] Zmigrod L, Garrison JR, Carr J, Simons JS. The neural mechanisms of hallucinations: a quantitative meta-analysis of neuroimaging studies. Neurosci Biobehav Rev 2016;69:113-23.

[28] Waters FA, Badcock JC, Michie PT, Maybery MT. Auditory hallucinations in schizophrenia: intrusive thoughts and forgotten memories. Cogn Neuropsychiatry 2006; 11(1):65-83.
[29] Northoff G, Qin P. How can the brain's resting state activity generate hallucinations? A 'resting state hypothesis' of auditory verbal hallucinations. Schizophr Res 2011;127(1-3):202-14

30] Palaniyappan L, Liddle PF. Does the salience network play a cardinal role in psychosis? An emerging hypothesis of insular dysfunction. Journal of Psychiatry \& Neuroscience 2012;37(1):17-27.

[31] Nazimek JM, Hunter MD, Woodruff PW. Auditory hallucinations: expectationperception model. Med Hypotheses 2012;78(6):802-10

[32] Collerton D, Perry E, McKeith I. Why people see things that are not there: a novel perception and attention deficit model for recurrent complex visual hallucinations. Behav Brain Sci 2005:28(6):737-57 [discussion 57-94].

[33] Hugdahl K. "Hearing voices": auditory hallucinations as failure of top-down control of bottom-up perceptual processes. Scand J Psychol 2009;50(6):553-60.

[34] Jardri R, Hugdahl K, Hughes M, et al. Are hallucinations due to an imbalance between excitatory and inhibitory influences on the brain? Schizophr Bull 2016;42 (5):1124-34.

[35] Fletcher PC, Frith CD. Perceiving is believing: a Bayesian approach to explaining the positive symptoms of schizophrenia. Nat Rev Neurosci 2009;10(1):48-58

[36] Muller AJ, Shine JM, Halliday GM, Lewis S]. Visual hallucinations in Parkinson's disease: theoretical models. Mov Disord 2014;29(13):1591-8.

[37] Powers III AR, Kelley M, Corlett PR. Hallucinations as top-down effects on perception. Biol Psychiatry Cogn Neurosci Neuroimaging 2016:1(5):393-400.

[38] Cho R, Wu W. Mechanisms of auditory verbal hallucination in schizophrenia. Front Psych 2013;4:155

39] Alderson-Day B, Diederen K, Fernyhough C, et al. Auditory hallucinations and the Brain's resting-state networks: findings and methodological observations. Schizophr Bull 2016;42(5):1110-23.

[40] Jones SR. Do we need multiple models of auditory verbal hallucinations? Examining the phenomenological fit of cognitive and neurological models. Schizophr Bull 2010;36(3):566-75

[41] Rolland B, Jardri R, Amad A, Thomas P, Cottencin O, Bordet R. Pharmacology of hallucinations: several mechanisms for one single symptom? Biomed Res Int 2014; 2014 \{Rolland, 2014 \#81\}. (307106).

[42] Curcic-Blake B, Ford JM, Hubl D, et al. Interaction of language, auditory and memory brain networks in auditory verbal hallucinations. Prog Neurobiol 2017;148: $1-20$.

[43] Garrison JR, Fernyhough C, McCarthy-Jones S, Haggard M, Australian Schizophrenia Research B, Simons JS. Paracingulate sulcus morphology is associated with hallucinations in the human brain. Nat Commun 2015;6:8956.

[44] Muller VI, Cieslik EC, Laird AR, et al. Ten simple rules for neuroimaging metaanalysis. Neurosci Biobehav Rev 2018;84:151-61.

[45] Allen P, Aleman A, McGuire PK. Inner speech models of auditory verbal hallucinations: evidence from behavioural and neuroimaging studies. International Review of Psychiatry 2007;19(4):407-15 Abingdon, England.

[46] Diederich NJ, Goetz CG, Stebbins GT. Repeated visual hallucinations in Parkinson's disease as disturbed external/internal perceptions: focused review and a new integrative model. Movement Disorders 2005;20(2):130-40.

[47] Moher D, Liberati A, Tetzlaff J, Altman DG, Group P. Preferred reporting items for systematic reviews and meta-analyses: the PRISMA statement. BMJ 2009;339: b2535.

[48] Radua J, Mataix-Cols D, Phillips ML, et al. A new meta-analytic method for neuroimaging studies that combines reported peak coordinates and statistical parametric maps. European Psychiatry 2012;27(8):605-11.

[49] Radua J, Rubia K, Canales-Rodriguez EJ, Pomarol-Clotet E, Fusar-Poli P, Mataix-Cols D. Anisotropic kernels for coordinate-based meta-analyses of neuroimaging studies. Front Psych 2014;5:13.

[50] Eickhoff SB, Laird AR, Grefkes C, Wang LE Zilles K, Fox PT. Coordinate-based activation likelihood estimation meta-analysis of neuroimaging data: a random-effects approach based on empirical estimates of spatial uncertainty. Hum Brain Mapp 2009;30(9):2907-26

[51] Llorca PM, Pereira B, Jardri R, et al. Hallucinations in schizophrenia and Parkinson's disease: an analysis of sensory modalities involved and the repercussion on patients. Sci Rep 2016;6:38152.

[52] van Swam C, Federspiel A, Hubl D, et al. Possible dysregulation of cortical plasticity in auditory verbal hallucinations-a cortical thickness study in schizophrenia. J Psychiatr Res 2012;46(8):1015-23.

[53] Smieskova R, Fusar-Poli P, Aston J, et al. Insular volume abnormalities associated with different transition probabilities to psychosis. Psychol Med 2012:42(8): $1613-25$

[54] Lee YM, Chung YI, Park JM, et al. Decreased gray matter volume is associated with the subtypes of psychotic symptoms in patients with antipsychotic-naive mild or moderate Alzheimer's disease: a voxel-based morphometry study. Psychiatry Res 2016;249:45-51.

[55] Radua J, Mataix-Cols D. Voxel-wise meta-analysis of grey matter changes in obsessive-compulsive disorder. The British Journal of Psychiatry 2009:195(5): 393-402

[56] Radua J, van den Heuvel OA, Surguladze S, Mataix-Cols D. Meta-analytical comparison of voxel-based morphometry studies in obsessive-compulsive disorder vs other anxiety disorders. Arch Gen Psychiatry 2010;67(7):701-11.

[57] Radua J, Romeo M, Mataix-Cols D, Fusar-Poli P. A general approach for combining voxel-based meta-analyses conducted in different neuroimaging modalities. Curr Med Chem 2013:20(3):462-6.

[58] Wise T, Radua J, Via E, Cardoner N, Abe O, Adams TM, et al. Common and distinct patterns of grey-matter volume alteration in major depression and bipolar disorder: evidence from voxel-based meta-analysis. Mol Psychiatry 2017;22(10): $1455-63$ 
[59] Gaser C, Nenadic I, Volz HP, Buchel C, Sauer H. Neuroanatomy of "hearing voices": a frontotemporal brain structural abnormality associated with auditory hallucinations in schizophrenia. Cerebral Cortex 2004;14(1):91-6 New York, NY: 1991.

[60] Shapleske J, Rossell SL, Chitnis XA, et al. A computational morphometric MRI study of schizophrenia: effects of hallucinations. Cerebral Cortex 2002;12(12):1331-41 New York, NY: 1991.

[61] van Tol MJ, van der Meer L, Bruggeman R, Modinos G, Knegtering H, Aleman A. Voxel-based gray and white matter morphometry correlates of hallucinations in schizophrenia: the superior temporal gyrus does not stand alone. Neurolmage Clinical 2014; 4: 249-57.

[62] Huang P, Xi Y, Lu ZL, et al. Decreased bilateral thalamic gray matter volume in firstepisode schizophrenia with prominent hallucinatory symptoms: a volumetric MRI study. Sci Rep 2015;5:14505.

[63] Neves MD, Duarte DG, Albuquerque MR, et al. Neural correlates of hallucinations in bipolar disorder. Rev Bras Psiquiatr 2016;38(1):1-5.

[64] Goldman JG, Stebbins GT, Dinh V, et al. Visuoperceptive region atrophy independent of cognitive status in patients with Parkinson's disease with hallucinations. Brain 2014;137(Pt 3):849-59.

[65] Meppelink AM, de Jong BM, Teune LK, van Laar T. Regional cortical grey matter loss in Parkinson's disease without dementia is independent from visual hallucinations. Movement Disorders 2011;26(1):142-7.

[66] Pagonabarraga J, Soriano-Mas C, Llebaria G, Lopez-Sola M, Pujol J, Kulisevsky J. Neural correlates of minor hallucinations in non-demented patients with Parkinson's disease. Parkinsonism Relat Disord 2014;20(3):290-6.

[67] Ramirez-Ruiz B, Marti MJ, Tolosa E, et al. Cerebral atrophy in Parkinson's disease patients with visual hallucinations. Eur J Neurol 2007;14(7):750-6.

[68] Watanabe H, Senda J, Kato S, et al. Cortical and subcortical brain atrophy in Parkinson's disease with visual hallucination. Movement Disorders 2013;28(12): 1732-6.

[69] Shin S, Lee JE, Hong JY, Sunwoo MK, Sohn YH, Lee PH. Neuroanatomical substrates of visual hallucinations in patients with non-demented Parkinson's disease. J Neurol Neurosurg Psychiatry 2012;83(12):1155-61.

[70] Blanc F, Noblet V, Philippi N, et al. Right anterior insula: core region of hallucinations in cognitive neurodegenerative diseases. PloS one 2014;9(12):e114774.

[71] Cierpka M, Wolf ND, Kubera KM, et al. Cerebellar contributions to persistent auditory verbal hallucinations in patients with schizophrenia. Cerebellum 2017;16 (5-6):964-72 London, England.

[72] Stanfield AC, Moorhead TW, Job DE, et al. Structural abnormalities of ventrolateral and orbitofrontal cortex in patients with familial bipolar disorder. Bipolar Disord 2009;11(2):135-44.

[73] Janzen J, van't Ent D, Lemstra AW, Berendse HW, Barkhof F, Foncke EM. The pedunculopontine nucleus is related to visual hallucinations in Parkinson's disease: preliminary results of a voxel-based morphometry study. J Neurol 2012;259(1): 147-54.

[74] Sanchez-Castaneda C, Rene R, Ramirez-Ruiz B, et al. Frontal and associative visual areas related to visual hallucinations in dementia with Lewy bodies and Parkinson's disease with dementia. Movement Disorders 2010;25(5):615-22.

[75] Colloby SJ, Elder GJ, Rabee R, O'Brien JT, Taylor JP. Structural grey matter changes in the substantia innominata in Alzheimer's disease and dementia with Lewy bodies: a DARTEL-VBM study. Int J Geriatr Psychiatry 2017;32(6):615-23.

[76] Kubera KM, Sambataro F, Vasic N, et al. Source-based morphometry of gray matter volume in patients with schizophrenia who have persistent auditory verbal hallucinations. Prog Neuropsychopharmacol Biol Psychiatry 2014;50: 102-9.

[77] Chen X, Liang S, Pu W, et al. Reduced cortical thickness in right Heschl's gyrus associated with auditory verbal hallucinations severity in first-episode schizophrenia. BMC Psychiatry 2015:15:152.

[78] Cui Y, Liu B, Song M, et al. Auditory verbal hallucinations are related to cortical thinning in the left middle temporal gyrus of patients with schizophrenia. Psychol Med 2017:1-8.

[79] Morch-Johnsen L, Nesvag R, Jorgensen KN, et al. Auditory cortex characteristics in schizophrenia: associations with auditory hallucinations. Schizophr Bull 2017;43 (1):75-83.

[80] Morch-Johnsen L, Nerland S, Jorgensen KN, et al. Cortical thickness abnormalities in bipolar disorder patients with a lifetime history of auditory hallucinations. Bipolar Disord 2018;20(7):647-57.

[81] Yun JY, Kim SN, Lee TY, Chon MW, Kwon JS. Individualized covariance profile of cortical morphology for auditory hallucinations in first-episode psychosis. Hum Brain Mapp 2016;37(3):1051-65.

[82] van Lutterveld R, van den Heuvel MP, Diederen KM, et al. Cortical thickness in individuals with non-clinical and clinical psychotic symptoms. Brain 2014;137(Pt 10):2664-9.

[83] Ffytche DH, Pereira JB, Ballard C, Chaudhuri KR, Weintraub D, Aarsland D. Risk factors for early psychosis in PD: insights from the Parkinson's progression markers initiative. J Neurol Neurosurg Psychiatry 2017;88(4):325-31.

[84] Delli Pizzi S, Franciotti R, Tartaro A, et al. Structural alteration of the dorsal visual network in DLB patients with visual hallucinations: a cortical thickness MRI study. PloS one 2014;9(1):e86624.

[85] Delli Pizzi S, Franciotti R, Bubbico G, Thomas A, Onofrj M, Bonanni L. Atrophy of hippocampal subfields and adjacent extrahippocampal structures in dementia with Lewy bodies and Alzheimer's disease. Neurobiol Aging 2016;40:103-9.

[86] Kubera KM, Thomann PA. Hirjak D, et al. Cortical folding abnormalities in patients with schizophrenia who have persistent auditory verbal hallucinations. European Neuropsychopharmacology 2018;28(2):297-306.

[87] Cachia A, Amad A, Brunelin J, et al. Deviations in cortex sulcation associated with visual hallucinations in schizophrenia. Mol Psychiatry 2015;20(9):1101-7.
[88] Rossell SL, Shapleske J, Fukuda R, Woodruff PW, Simmons A, David AS. Corpus callosum area and functioning in schizophrenic patients with auditory-verbal hallucinations. Schizophr Res 2001;50(1-2):9-17.

[89] Shapleske J, Rossell SL, Simmons A, David AS, Woodruff PW. Are auditory hallucinations the consequence of abnormal cerebral lateralization? A morphometric MR study of the sylvian fissure and planum temporale. Biol Psychiatry 2001;49(8): 685-93.

[90] Hubl D, Dougoud-Chauvin V, Zeller M, et al. Structural analysis of Heschl's gyrus in schizophrenia patients with auditory hallucinations. Neuropsychobiology 2010;61 (1):1-9.

[91] Amad A, Cachia A, Gorwood P, et al. The multimodal connectivity of the hippocampal complex in auditory and visual hallucinations. Mol Psychiatry 2014;19(2): 184-91.

[92] Shin SE, Lee JS, Kang MH, Kim CE, Bae JN, Jung G. Segmented volumes of cerebrum and cerebellum in first episode schizophrenia with auditory hallucinations. Psychiatry Res 2005;138(1):33-42.

[93] Pereira JB, Junque C, Bartres-Faz D, Ramirez-Ruiz B, Marti MJ, Tolosa E. Regional vulnerability of hippocampal subfields and memory deficits in Parkinson's disease. Hippocampus 2013;23(8):720-8.

[94] Yao N, Cheung C, Pang S, et al. Multimodal MRI of the hippocampus in Parkinson's disease with visual hallucinations. Brain Struct Funct 2016;221(1):287-300.

[95] Lin SH, Yu CY, Pai MC. The occipital white matter lesions in Alzheimer's disease patients with visual hallucinations. Clin Imaging 2006;30(6):388-93.

[96] Morch-Johnsen L, Nesvag R, Jorgensen KN, et al. Auditory cortex characteristics in schizophrenia: associations with auditory hallucinations. Schizophr Bull 2017;43 (1):75-83.

[97] Hutton C, Draganski B, Ashburner J, Weiskopf N. A comparison between voxelbased cortical thickness and voxel-based morphometry in normal aging. Neurolmage 2009;48(2):371-80.

[98] Lenka A, Jhunjhunwala KR, Saini J, Pal PK. Structural and functional neuroimaging in patients with Parkinson's disease and visual hallucinations: a critical review. Parkinsonism Relat Disord 2015;21(7):683-91.

[99] Alderson-Day B, McCarthy-Jones S, Fernyhough C. Hearing voices in the resting brain: a review of intrinsic functional connectivity research on auditory verbal hallucinations. Neurosci Biobehav Rev 2015;55:78-87.

[100] Ford JM, Palzes VA, Roach BJ, Potkin SG, van Erp TG, Turner JA, et al. Visual hallucinations are associated with hyperconnectivity between the amygdala and visual cortex in people with a diagnosis of schizophrenia. Schizophr Bull 2015;41(1): 223-32.

[101] Yao N, Shek-Kwan Chang R, Cheung C, et al. The default mode network is disrupted in Parkinson's disease with visual hallucinations. Hum Brain Mapp 2014;35(11): 5658-66.

[102] Horga G, Schatz KC, Abi-Dargham A, Peterson BS. Deficits in predictive coding underlie hallucinations in schizophrenia. J Neurosci 2014;34(24):8072-82.

[103] Goodkind M, Eickhoff SB, Oathes DJ, et al. Identification of a common neurobiolog ical substrate for mental illness. JAMA Psychiat 2015;72(4):305-15.

[104] Zeighami Y, Ulla M, Iturria-Medina Y, et al. Network structure of brain atrophy in de novo Parkinson's disease. Elife 2015;4.

[105] Simons JS, Garrison JR, Johnson MK. Brain mechanisms of reality monitoring. Trends Cogn Sci 2017;21(6):462-73.

106] Raij TT, Valkonen-Korhonen M, Holi M, Therman S, Lehtonen J, Hari R. Reality of auditory verbal hallucinations. Brain 2009;132(Pt 11):2994-3001.

[107] Niemantsverdriet MBA, Slotema CW, Blom JD, et al. Hallucinations in borderline personality disorder: prevalence, characteristics and associations with comorbid symptoms and disorders. Sci Rep 2017;7(1):13920.

[108] Raine A. Antisocial personality as a neurodevelopmental disorder. Annu Rev Clin Psychol 2018:14:259-89.

[109] Bolkan SS, Stujenske JM, Parnaudeau S, et al. Thalamic projections sustain prefrontal activity during working memory maintenance. Nat Neurosci 2017;20(7): 987-96.

[110] Aminoff EM, Kveraga K, Bar M. The role of the parahippocampal cortex in cognition. Trends Cogn Sci 2013;17(8):379-90.

[111] Luhrmann TM, Padmavati R, Tharoor H, Osei A. Differences in voice-hearing experiences of people with psychosis in the U.S.A., India and Ghana: interview-based study. The British Journal of Psychiatry 2015;206(1):41-4.

[112] Slotema CW, Blom JD, van Lutterveld R, Hoek HW, Sommer IE. Review of the efficacy of transcranial magnetic stimulation for auditory verbal hallucinations. Biol Psychiatry 2014;76(2):101-10.

[113] Otani VH, Shiozawa P, Cordeiro Q, Uchida RR. A systematic review and metaanalysis of the use of repetitive transcranial magnetic stimulation for auditory hallucinations treatment in refractory schizophrenic patients. Int J Psychiatry Clin Pract 2015;19(4):228-32.

[114] Nathou C, Simon G, Dollfus S, Etard O. Cortical anatomical variations and efficacy of rTMS in the treatment of auditory hallucinations. Brain Stimul 2015;8 (6):1162-7.

[115] Sommer IE, Slotema CW, Daskalakis ZJ, Derks EM, Blom JD, van der Gaag M. The treatment of hallucinations in schizophrenia spectrum disorders. Schizophr Bul 2012;38(4):704-14.

[116] Ffytche DH, Creese B, Politis M, et al. The psychosis spectrum in Parkinson disease Nat Rev Neurol 2017;13(2):81-95.

[117] McCarthy-Jones S, Smailes D, Corvin A, et al. Occurrence and co-occurrence of hallucinations by modality in schizophrenia-spectrum disorders. Psychiatry Res 2017; 252:154-60.

[118] Stevenson RJ, Langdon R, McGuire J. Olfactory hallucinations in schizophrenia and schizoaffective disorder: a phenomenological survey. Psychiatry Res 2011;185(3): 321-7. 
[119] Krakvik B, Laroi F, Kalhovde AM, et al. Prevalence of auditory verbal hallucinations in a general population: a group comparison study. Scand J Psychol 2015;56(5): 508-15.

[120] Xu Y, Yang J, Hu X, Shang H. Voxel-based meta-analysis of gray matter volume reductions associated with cognitive impairment in Parkinson's disease. J Neurol 2016;263(6):1178-87.

[121] Fusar-Poli P. Voxel-wise meta-analysis of fMRI studies in patients at clinical high risk for psychosis. Journal of Psychiatry \& Neuroscience 2012;37(2):106-12.
[122] Plaze M, Paillere-Martinot ML, Penttila J, et al. "Where do auditory hallucinations come from?"-a brain morphometry study of schizophrenia patients with inner or outer space hallucinations. Schizophr Bull 2011;37(1):212-21.

[123] Dudley R, Aynsworth C, Cheetham R, McCarthy-Jones S, Collerton D. Prevalence and characteristics of multi-modal hallucinations in people with psychosis who experience visual hallucinations. Psychiatry Res 2018;269:25-30. 